\title{
Molecular mechanisms activating the NAIP-NLRC4 inflammasome: implications in infectious disease, autoinflammation and cancer
}

Callum Kay ${ }^{1}$, Runli Wang ${ }^{1}$, Max Kirkby ${ }^{1}$, and Si Ming Man ${ }^{1}$

1 Department of Immunology and Infectious Disease, The John Curtin School of Medical Research, The Australian National University, Canberra, Australia.

Correspondence to:

Si Ming Man

E-mail: siming.man@anu.edu.au

Keywords: Gasdermin, IL-1 $\beta$, IL-18, inflammatory caspases, pyroptosis. 


\section{Abstract}

Cytosolic innate immune sensing is a cornerstone of innate immunity in mammalian cells and provides a surveillance system for invading pathogens and endogenous danger signals. The NAIP-NLRC4 inflammasome responds to cytosolic flagellin, and the inner rod and needle proteins of the type 3 secretion system of bacteria. This complex induces proteolytic cleavage of the proinflammatory cytokines IL-1 $\beta$ and IL-18, and the pore-forming protein gasdermin $D$, leading to inflammation and pyroptosis, respectively. Localized responses triggered by the NAIP-NLRC4 inflammasome are largely protective against bacterial pathogens, owing to several mechanisms, including the release of inflammatory mediators, liberation of concealed intracellular pathogens for killing by other immune mechanisms, activation of apoptotic caspases, caspase-7 and caspase-8, and expulsion of an entire infected cell from the mammalian host. In contrast, aberrant activation of the NAIP-NLRC4 inflammasome caused by de novo gain-of-function mutations in the gene encoding NLRC4 can lead to macrophage activation syndrome, neonatal enterocolitis, fetal thrombotic vasculopathy, familial cold autoinflammatory syndrome and even death. In addition, the NAIP-NLRC4 inflammasome has been implicated in the pathogenesis of colorectal cancer, melanoma, glioma and breast cancer. However, no consensus has been reached on its function in the development of any cancer types. In this review, we highlight the latest advances in the activation mechanisms and structural assembly of the NAIP-NLRC4 inflammasome, and the functions of this inflammasome in different cell types. We also describe progress towards understanding the role of the NAIP-NLRC4 inflammasome in infectious diseases, autoinflammatory diseases and cancer. 


\section{Introduction}

The innate immune system is the first line of defense in the host response against microbial infection. Innate immune recognition is initiated by pattern-recognition receptors (PRRs), which include inflammasome sensors. Inflammasomes are multicomponent innate immune signaling complexes that can assemble in response to PRR-mediated recognition of pathogen-associated molecular patterns (PAMPs), danger-associated molecular patterns (DAMPs) and homeostasis-altering molecular processes (HAMPs) ${ }^{1-3}$. Inflammasome sensors include the nucleotide-binding domain and leucine-rich repeat receptors (NLRs) NLRP1, NLRP3, NLR apoptosis inhibitory protein (NAIP), NLRC4, NLRP6 and NLRP9. In addition, AIM2 from the AIM2-like receptor family and Pyrin from the Tripartite motif family can also initiate inflammasome complex formation ${ }^{4-6}$.

Activation of inflammasome sensors leads to the recruitment of the adaptor protein apoptosisassociated speck-like protein containing a CARD (ASC). ASC is a bipartite protein, containing a pyrin domain (PYD) and a caspase activation and recruitment domain (CARD). In this way, ASC couples activation of the upstream PRR to the activation of the effector cysteine protease caspase- $1^{7}$. Recruitment of caspase-1 induces its self-dimerization, activating its catalytic activity. Active caspase-1 then proteolytically cleaves the proinflammatory cytokines prointerleukin (IL)-1 $\beta$ and pro-IL-18 into their mature forms. Human caspase-4 and caspase-5 and mouse caspase-11 also form inflammasome complexes following binding to cytosolic LPS 8-12. Inflammasome caspases induce proteolytic cleavage of the pore-forming protein gasdermin D (GSDMD) ${ }^{13-15}$. Cleavage of GSDMD relieves the $\mathrm{N}$-terminal domain from the autoinhibitory $\mathrm{C}$-terminal domain, allowing the $\mathrm{N}$-terminal domain to oligomerize in the host cell membrane, resulting in pore formation that causes a lytic and inflammatory form of cell death known as pyroptosis ${ }^{16,17}$.

This review will discuss recent progress in the biology of the NAIP-NLRC4 inflammasome. Specifically, we will focus on mechanisms of ligand detection and recognition by NAIP proteins, the structural and regulatory features of the NAIP-NLRC4 inflammasome, the distinct cell types expressing NLRC4 and its cell type-specific roles, and the role of this inflammasome in infectious and autoinflammatory diseases. We also discuss the emerging but often contentious role of this inflammasome in cancer. Finally, we identify some unanswered questions and highlight areas which would be of interest to investigate in future studies on the NAIP-NLRC4 inflammasome biology in human health and disease. 


\section{Discovery and early characterization of NLRC4}

NLRC4 was first identified by a search of genes with sequence similarity to caspase-1, and proteins with structural homology to the apoptotic protease activating factor-1 (APAF-1) protein ${ }^{18}$. This early study identified a cytoplasmic protein capable of inducing cleavage and activation of the interleukin-1 converting enzyme (ICE, now known as caspase-1), and it was hence named ICE-protease activating factor, or IPAF ${ }^{18}$. IPAF carries a nucleotide-binding domain (NBD, also known as a NACHT), a leucine-rich repeats domain (LRRs) and a caspase activation and recruitment domain (CARD). These domain features give rise to its current nomenclature within the NBD and LRRs (NLR) family, NLRC4 (Figure 1A) ${ }^{19}$.

The first genetic evidence that NLRC4 might assemble an endogenous inflammasome complex was provided in 2004 by experiments showing that wild-type (WT), but not NLRC4deficient $\left(\mathrm{NIrC4}^{--}\right)$mouse bone marrow-derived macrophages (BMDMs) underwent activation of caspase-1, release of IL-1 $\beta$, and pyroptosis following infection with the foodborne bacterium Salmonella enterica serovar Typhimurium (herein referred to as $S$. Typhimurium) ${ }^{20}$. Moreover, ATP induced activation of caspase-1, release of IL-1 3 , and pyroptosis in both WT and NIrc4I- BMDMs, indicating a level of specificity of NLRC4 towards cytosolic sensing of $S$. Typhimurium ${ }^{20}$.

Two studies in 2006 further identified flagellin, a monomeric component of the bacterial flagellum apparatus involved in motility and chemotaxis, as an activator of the NLRC4 inflammasome ${ }^{21,22}$. These studies showed that $S$. Typhimurium strains lacking components of the flagellar apparatus, such as fliC and fljB, failed to activate NLRC4 in BMDMs, and that WT but not $\mathrm{NIrC4}^{-1-}$ BMDMs, responded to the transfection of $S$. Typhimurium flagellin into the cytoplasm. A further study showed that the flagellin of the Gram-negative bacterium Legionella pneumophila induced activation of the NLRC4 inflammasome in BMDMs ${ }^{23}$. These findings collectively demonstrated for the first time that flagellin is a key activator of NLRC4 and extended the frontiers of our understanding of innate immune recognition (Figure 1B). The concept that the same microbial ligand can be detected in mammalian immune cells in a compartmentalized manner is realized: Toll-like receptor 5 (TLR5) recognizes flagellin from the surface of the cell ${ }^{24}$, whereas NLRC4 recognizes flagellin from within the cytoplasm.

Subsequent studies observed that, in some cases, the NLRC4 inflammasome could be activated by bacteria without flagellin ${ }^{22}$. Indeed, further work revealed that the NLRC4 inflammasome is activated by virulence factors with a similar structure and/or function to flagellin, such as certain proteins of the type 3 secretion system (T3SS) derived from many 
bacterial pathogens (Figure 1B). These pathogens and their associated proteins include $S$. Typhimurium (PrgJ), Burkholderia pseudomallei (BsaK), Escherichia coli (EprJ and Escl), Shigella flexneri (Mxil) and Pseudomonas aeruginosa (Pscl) ${ }^{25}$. These findings position NLRC4 as an innate immune sensor capable of exploiting the structural and functional conservation of bacterial virulence factors.

\section{NAIPs confer ligand specificity}

It was speculated that NLRC4 might bind flagellin and certain virulence factors of the T3SS, however no study had been able to show a direct interaction between these ligands and NLRC4. Another possibility was that NLRC4 might recruit an adaptor protein for ligand recognition. Indeed, a study suggested that NLRC4 could form heterotypic complexes with other NACHT-containing proteins ${ }^{26}$. One such NACHT-containing protein already implicated in inflammasome activation was NAIP5 in mice, since it was required for flagellin-mediated inflammasome activation ${ }^{27}$ but not for flagellin-independent NLRC4 inflammasome activation 28.

Indeed, two studies published in 2011 identified that NAIP proteins acted as upstream sensors of NLRC4-activating ligands ${ }^{29,30}$. Specifically, they demonstrated that mouse NAIP2 and mouse NAIP5 directly and specifically interacted with the T3SS inner rod protein and flagellin, respectively (Figure 1B). Further work demonstrated that mouse NAIP1 recognized the T3SS needle protein ${ }^{31,32}$, and that mouse NAIP6 sensed flagellin, redundantly to mouse NAIP5 ${ }^{30}$. The identification of mouse NAIP paralogues as distinct ligand sensors provides a convincing explanation for how NLRC4 could detect multiple bacterial ligands (Figure 1B). Further, genetic deletion of NAIPs in mice confirmed their importance in mediating ligand specificity ${ }^{33-}$ 35 .

The murine genome encodes seven NAIP proteins, while the human genome only encodes a single functional NAIP protein (hNAIP) ${ }^{36}$. Initially it was shown that hNAIP was functionally analogous to murine NAIP1, sensing the T3SS needle protein ${ }^{31,32}$. Additional studies have revealed that hNAIP can mediate NLRC4 inflammasome activation in response to both T3SS components and flagellin ${ }^{37,38}$. Notably, it has been suggested that a longer hNAIP isoform confers flagellin sensitivity ${ }^{37}$, but ectopic expression of this longer isoform in HEK293 cells sensitized them to NLRC4 inflammasome activation by flagellin and T3SS needle and inner rod proteins ${ }^{38}$. The presence of a single NAIP in humans that can sense multiple distinct ligands is intriguing and indicates differential division of labor for recognition of bacterial ligands compared to murine NAIPs. It should be noted that only the needle protein of the 
Gram-negative bacterium Chromobacterium violaceum (Cprl) has been shown to directly interact with hNAIP ${ }^{29}$. It remains unclear whether flagellin and T3SS inner rod protein are also directly bound by hNAIP, and how a single sensor might recognize these distinct ligands.

\section{Structural insights into NAIP-NLRC4 inflammasome assembly}

Inflammasome assembly must be tightly regulated to avoid inappropriate activation that would cause inflammatory damage to the host ${ }^{39}$. Inflammasome activation is initiated by sensor activation and oligomerization, which provides a site for ASC and/or caspase-1 recruitment ${ }^{40}$. In the case of the NAIP-NLRC4 inflammasome, activation requires (1) ligand interaction with an inactive NAIP protein, (2) ligand-induced activation of the NAIP protein, (3) ligand-NAIP induced interaction with an inactive NLRC4 monomer, (4) activation of an NLRC4 monomer, (5) active NLRC4 interaction with an inactive NLRC4 monomer and (6) the successive addition of NLRC4 monomers ${ }^{41,42}$.

Structural and mechanistic studies have provided profound insights into the process of NAIPNLRC4 inflammasome assembly. In the first step, an activating ligand (flagellin or T3SS needle or inner rod proteins) interacts with an inactive NAIP protein and causes a conformational change in the NAIP protein that relieves autoinhibition. This step is illustrated by the example of the flagellin-NAIP5 interaction: the D0 domain of flagellin is able to make contact with six domains of NAIP5, forcing it to convert into an active conformation ${ }^{43}$. Whilst structural insights are lacking for the other ligand-NAIP partners, it is assumed that they proceed via a similar mechanism of ligand-induced NAIP activation. It has been reported that multisurface ligand recognition is common to NAIPs. Mutagenic studies found that whilst mutation of these key recognition motifs in the ligand enabled immune evasion by NAIP5, it also disrupted flagellar motility ${ }^{43}$. This observation, coupled with the fact that the membranelocalized flagellin sensor TLR5 senses a conserved and functionally important site in the D1 domain of flagellin ${ }^{44}$, limits pathogen immune evasion ${ }^{43}$. Interestingly, whilst the LRRs has been proposed to act as a sensor for NLR ligands ${ }^{45,46}$, studies have revealed that ligand specificity by NAIPs is mediated by an internal region containing NBD-associated $\alpha$-helices (in particular the helical domain 1 or HD1, winged-helix domain or WHD, and helical domain 2 or HD2) rather than the LRRs ${ }^{47}$.

Once a NAIP protein has become activated by its respective ligand, it can interact with an inactive NLRC4 monomer. The inactive NLRC4 monomer has been structurally characterized by X-ray crystallography and revealed that an ADP-mediated interaction between the central NBD and WHD domains stabilized the closed conformation of NLRC4. The same study found 
that the C-terminal LRRs was positioned to sterically occlude one surface of the NBD and sequester NLRC4 in a monomeric state ${ }^{48}$. The authors also demonstrated that mutagenesis abolishing crucial inhibitory interactions lead to constitutive NLRC4 inflammasome activation and bypassed the requirement for flagellin ${ }^{48}$. Indeed, we will discuss below the clinical importance and consequences of mutations in humans leading to constitutive activation of the NLRC4 inflammasome.

Once a ligand-bound NAIP complex interacts with NLRC4, it is sufficient to trigger conformational changes in NLRC4, driving it towards an active conformation ${ }^{41,42}$. Activation of an NLRC4 monomer is mediated by a $90^{\circ}$ conformational rotation in the hinge region between HD1 and WHD. This conformational change exposes a largely basic 'catalytic surface' on the active NLRC4 that can interact with the largely acidic 'receptor surface' on an incoming inactive NLRC4 monomer. This interaction activates the second NLRC4 monomer, which can recruit additional NLRC4 monomers and leads to a self-propagation mechanism resulting in the formation of a 10-12 subunit wheel-like structure ${ }^{41,42}$. Importantly, NAIPs also possess a 'catalytic surface' that matches the 'receptor surface' of NLRC4 and enables initiation of oligomerization, but they do not possess a receptor side and therefore only a single NAIP is found per NAIP-NLRC4 inflammasome complex 41,42. Unlike apoptosome oligomerization, which requires one cytochrome $c$ ligand per APAF-1 monomer ${ }^{49}$, the NAIPNLRC4 inflammasome only requires a single bound ligand to initiate oligomerization. This point of difference suggests that the NAIP-NLRC4 inflammasome can respond to a lower concentration of activating ligand and that different cell death pathways have different thresholds for initiation.

\section{NLRC4 activation by phosphorylation}

Inflammasome components, including NLRC4, are subject to post-translational modifications that can regulate their assembly and function ${ }^{50-53}$. Earlier work in murine BMDMs identified that NLRC4 was phosphorylated at position S533 by Protein Kinase C delta (PKC- $\delta)$ in response to $S$. Typhimurium infection, and suggested that this modification was required for NLRC4 inflammasome assembly (Figure 1B) ${ }^{54}$. The importance of PKC- $\delta$ and phosphorylation at S533 in NLRC4 inflammasome activation has been questioned in subsequent work. For example, using an independently generated mouse strain lacking PKC$\delta$, both $S$. Typhimurium and $S$. flexneri were found to induce activation of the NLRC4 inflammasome independently of PKC- ${ }^{55}$. It is important to note that additional kinases can phosphorylate NLRC4 besides PKC- $\delta$. Indeed, the leucine rich repeat kinase (LRRRK) 2 has also been shown to phosphorylate NLRC4 at S533 ${ }^{56}$, suggesting possible functional 
redundancy between kinases inducing phosphorylation of NLRC4. However, Helicobacter pylori flagellin can induce NLRC4 phosphorylation but does not lead to inflammasome activation ${ }^{57}$, suggesting that NLRC4 phosphorylation is insufficient for inflammasome activation. These findings were supported by the observation that S533 is phosphorylated in the inactive NLRC4 monomer ${ }^{48}$.

The requirement for phosphorylation of NLRC4 at S533 in the activation of the NLRC4 inflammasome was initially supported by at least two lines of evidence. First, immortalized mouse macrophages from $\mathrm{NIrC4}^{-1-}$ mice were reconstituted either with WT NLRC4 or a nonphosphorylatable S533A NLRC4 mutant. This experiment revealed that macrophages carrying the mutant S533A NLRC4 had an impaired ability to induce activation of the inflammasome in response to $S$. Typhimurium infection compared with macrophages carrying WT NLRC4 ${ }^{54}$. Second, the same group generated a mouse strain carrying a non-

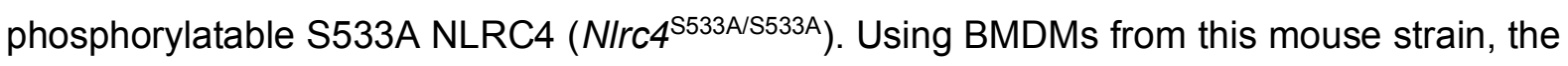
authors showed that NIrc4 ${ }^{\text {S533A/S533A }}$ BMDMs induced activation of the NLRC4 inflammasome with a delayed kinetics following infection with $S$. Typhimurium compared to WT BMDMs ${ }^{58}$. Given that previous studies showed that both NLRC4 and NLRP3 collectively induce activation of the inflammasome in response to $S$. Typhimurium infection ${ }^{59,60}$, the authors generated a NIrc $4^{\text {S533A/S533A }}$ mouse strain lacking NLRP3. BMDMs from NIrc4 ${ }^{\text {S533ASS533A }} \mathrm{NIrp3}^{-1-}$ mice had a substantially impaired ability to induce activation of the inflammasome in response to $S$. Typhimurium infection ${ }^{58}$. Therefore, the authors concluded that phosphorylation of NLRC4 at S533 is important for activation of the NLRC4 inflammasome.

A further study generated several new mouse strains to clarify the role of S533 phosphorylation and NLRC4 inflammasome activation. These mouse strains include a NIrc4 $4^{\text {S533A/S533A }}$ mouse strain, and a NIrc4 ${ }^{\text {S533A/S533A }}$ NIrp3 $^{-1-}$ mouse strain. They reported no difference in inflammasome activation between WT and NIrc4 ${ }^{\text {S533A/S533A }}$ BMDMs when a higher dose of $S$. Typhimurium was used (multiplicity of infection of 5), but a minor decrease in the activation of the inflammasome was observed in NIrc4 ${ }^{\text {S533A/S533A }}$ BMDMs when a lower dose of $S$. Typhimurium was used (multiplicity of infection of 1$)^{61}$. Further, the use of WT BMDMs versus NIrc4 ${ }^{\text {S533ASS533A }} \mathrm{NIrp3}^{-1-}$ BMDMs did not reveal a greater level of difference ${ }^{61}$. Differences in the CB57BL/6 substrains used between studies is a potential explanation for these discrepancies, given that the latest study used the C57BL/6J substrain ${ }^{61}$, whereas the previous studies presumably used the C57BL/6N substrain $20,54,58$. Regardless, the subtle contribution of S533 phosphorylation in NLRC4 inflammasome activation might suggest that post-translational modifications at multiple sites of NLRC4, rather than only at S533, would be required for optimal activation. Further, perhaps the subtlety in the requirement for S533 
phosphorylation is mouse-specific, and that a more prominent role for phosphorylation would be observed in cells from humans or other mammalian species.

\section{Other regulatory mechanisms}

Evidence suggests that NLRC4 is regulated by ubiquitination. Notably, an interaction between NLRC4 and the suppressor of Gal 1 (SUG1) has been reported, which leads to NLRC4 ubiquitination and caspase-8-mediated cell death in human lung carcinoma A549 cells ${ }^{62}$. This finding is supported by another study showing that an autoinflammatory mutant of NLRC4 (site His433Pro) enabled a stronger interaction with SUG1, leading to enhanced caspase-8mediated cell death even in the absence of S533 phosphorylation ${ }^{63}$. It is possible that modifications such as ubiquitination of NLRC4 might compensate for a lack of phosphorylation, however this is yet to be validated.

Whilst NAIPs are critical in NLRC4 inflammasome activation, there is no report of their posttranslational regulation. However, a study has demonstrated that both NAIPs and NLRC4 are transcriptionally induced by interferon regulatory factor (IRF) $8{ }^{64}$. Mechanistically, IRF8 was reported to act as a transcriptional activator for murine NAIPs 1, 2, 5 and 6, and NLRC4. Interestingly, this study showed that NLRC4 inflammasome activation in Irf8 ${ }^{-/-}$BMDMs was not completely abrogated, suggesting that additional factors contribute to the transcriptional regulation of NAIPs and NLRC4 ${ }^{64}$. One such factor might be the transcription factor SPI1 (also known as PU.1), which interacts with another transcription factor IRF4 and is required to drive $B$ cell transcriptional processes ${ }^{65}$, however this requires further investigation. Additionally, IRF8 peaks were not found in chromatin immunoprecipitation sequencing data at the NAIP1 locus but were found at the other NAIP loci ${ }^{64}$. It is possible that NAIP1 may be regulated differently to the other NAIPs, which is supported by the observation that NAIP1 required additional priming signals, such as poly $(\mathrm{l}: \mathrm{C})^{31}$. Lastly, negative regulators of the NLRC4 inflammasome have also been identified, including the B cell adaptor for phosphoinositide 3-kinase ${ }^{66}$, heat shock cognate protein $70{ }^{67}$, the $S$. Typhimurium SopB protein ${ }^{68}$ and the tick protein sialostatin L2 ${ }^{69}$.

\section{NLRC4 is expressed in multiple cell types}

Inflammasome complexes have been extensively studied in mouse macrophages, however emerging evidence indicates that inflammasome components are expressed and functional in a variety of cell types, including those of hematopoietic and non-hematopoietic origin (Figures

\section{2 and 3).}


Earlier studies have demonstrated that components of the NAIP-NLRC4 inflammasome are all expressed in mouse BMDMs (Figure 2), and thus, many of the mechanistic studies are performed using this cell type. For example, BMDMs lacking NAIPs or NLRC4 have an impaired ability to induce cleavage of caspase-1 and pro-IL-1 $\beta$ and undergo pyroptosis, in response to infection by bacteria such as $S$. Typhimurium or $L$. pneumophila ${ }^{21,22,70}$. Further work has revealed that the NAIP-NLRC4 inflammasome is activated in human monocytes and macrophages in response to $S$. Typhimurium infection ${ }^{29,31,71}$. Additionally, there is increasing evidence that other immune cells, such as dendritic cells, also express NLRC4 and can form functional inflammasome complexes (Figures 2 and 3) ${ }^{72-74}$.

In mouse neutrophils, the NLRC4 inflammasome can be activated to secrete IL-1 $\beta$ upon stimulation with $S$. Typhimurium ${ }^{75}$. A study has shown that NLRC4 inflammasome activation in the cell type expressing the Myeloid-related protein 8 , predominantly composed of neutrophils, causes systemic inflammation in mice ${ }^{76}$. Therefore, if left uncontrolled, activation of the NLRC4 inflammasome in neutrophils can be detrimental. Unlike macrophages, neutrophils resist pyroptosis in response to NLRC4 and other canonical inflammasome activation ${ }^{75}$. The lack of pyroptosis in neutrophils undergoing NLRC4 activation suggests that neutrophil extracellular traps, a network of chromatin and antimicrobial proteins, cannot be released. This is in contrast to neutrophils undergoing caspase-11 activation, which readily release neutrophil extracellular traps to kill bacteria ${ }^{77}$. This difference might suggest that the function of the NLRC4 inflammasome in neutrophils is more targeted towards sustaining inflammation at the site of infection. Indeed, neutrophils have been implicated as the major producers of IL-1 $\beta$ during acute bacterial infection ${ }^{75,78}$.

Bone marrow chimera experiments have revealed important antimicrobial functions for NLRC4 in non-hematopoietic cells in mice. These studies demonstrated that NLRC4 is highly expressed in intestinal epithelial cells and that NLRC4 has a protective role against the enteric pathogen $S$. Typhimurium, via mechanisms such as expulsion of infected intestinal epithelial cells ${ }^{79-81}$. These mechanisms of action will be discussed in more detail below.

NLRC4 is also expressed in the brain, predominantly in astrocytes and microglia ${ }^{18,82}$. It has been shown that the NLRC4 inflammasome can respond to bacterial flagellin in both of these cell types ${ }^{82}$. Interestingly, emerging studies suggest that astrocytic NLRC4 can respond to additional stimuli, including the central nervous system-associated DAMP lysophosphatidylcholine (LPC) and the fatty acid palmitate ${ }^{82,83}$. Furthermore, microglia have been reportedly activated following ischemia, and NLRC4 is implicated in ischemic brain injury 
84,85 . The potential of the NLRC4 inflammasome in glial cells to be activated by non-bacterial ligands puts forward the intriguing proposition that it may be activated in response to a novel endogenous danger-associated ligand or stimulus. This will be an exciting area of future research into NLRC4 inflammasome biology.

\section{NLRC4 and NAIPs in infectious diseases}

\section{$\underline{\text { Host defense against S. Typhimurium }}$}

The physiological role of the NLRC4 inflammasome has been explored using several bacterial infection models, most notably with the foodborne bacterium $S$. Typhimurium (Table 1). Studies have shown that mice lacking NLRC4 infected with S. Typhimurium either have no difference in bacterial burden in the spleen, liver or mesenteric lymph nodes compared to WT mice $59,86,87$, or that they succumbed to infection more quickly and had increased bacterial loads in the cecum, liver and spleen compared to WT mice ${ }^{60,61,79-81,87}$. The subtlety of the effect of NLRC4 in response to $S$. Typhimurium infection might be owing to its functional redundancies with another inflammasome sensor, NLRP3 ${ }^{59,60}$. Indeed, S. Typhimurium can activate the NLRC4 and NLRP3 inflammasomes in mouse BMDMs ${ }^{58-60}$. Mice lacking NLRC4 or NLRP3 individually were still capable of conferring some or little protection against $S$. Typhimurium 59,60,86,87. Mice lacking both NLRC4 and NLRP3 infected with S. Typhimurium exhibited elevated bacterial loads in the spleen, liver and mesenteric lymph nodes and reduced circulating IL-18 similar to mice lacking both caspase-1 and caspase-11, with both groups of mice showing increased susceptibility to the infection compared to WT mice ${ }^{59}$.

Further, previous studies have established that the routes used for $S$. Typhimurium infection and the genetic background of mice can determine the effectiveness of NLRC4 in preventing bacterial infection (Table 1). For example, difference in the bacterial burden in the spleen or liver was observed between WT mice and mice lacking NLRC4 on the BALB/c background following an orogastric infection, but not following an intraperitoneal infection ${ }^{87}$. Either an increase or a lack of difference in bacterial burden has been reported between WT mice and mice lacking NLRC4 on the C57BL/6 background following an orogastric infection ${ }^{59,88}$. In response to intravenous infection with $S$. Typhimurium, studies have reported either an increase or a lack of difference in bacterial burden in mice lacking NLRC4 compared to WT mice ${ }^{60,88}$. These studies indicate that the subtle effect of NLRC4 in response to $S$. Typhimurium in mice could be owing to the routes of administration, doses of bacteria used, functional redundancies between inflammasome sensors, and differences in background genetics and gut microbiota of mice housed in different facilities (Table 1). 
NLRC4 is expressed in both immune and non-immune cells (Figure 2 and 3). Studies using bone marrow chimeric mice have shown that, in an orogastric infection model of $S$. Typhimurium, NLRC4-deficient mice with a WT bone marrow reconstitution had elevated bacterial loads in the cecum compared with WT mice with a WT bone marrow reconstitution ${ }^{80}$. This finding argues that NLRC4 expressed in non-hematopoietic-derived cells are essential for protection against $S$. Typhimurium. Indeed, transcriptional and protein analyses have revealed that the expression of NLRC4 is among the highest in the cecum and small intestine compared to other tissues in mice ${ }^{75,87}$. This raised the question of whether NLRC4 expressed in intestinal cells may have a more dominant role in the protection against enteric pathogens infecting the lower regions of the gut, such as $S$. Typhimurium. Subsequent studies showed that cre-driven expression of NLRC4 in intestinal epithelial cells reduced the bacterial burden in the cecum of NLRC4-deficient mice infected with $S$. Typhimurium ${ }^{81}$. Further, tissue-specific knockout of NAIP1-6 in intestinal epithelial cells led to increased S. Typhimurium colonization in the gut of mice following orogastric infection ${ }^{80}$.

The mechanisms of protection induced by the NAIP-NLRC4 inflammasome in the gut requires expulsion of infected intestinal epithelial cells ${ }^{80}$. While caspase-1 and GSDMD are considered to be the terminal effectors of NLRC4-driven activities ${ }^{89}$, a study has shown that both caspase1 and caspase- 8 are required for cell expulsion from the intestinal epithelium, whereas caspase-1 and GSDMD alone are only sufficient for IL-18 secretion but not cell expulsion ${ }^{81}$. This study adds to the growing body of literature indicating that NLRC4 inflammasome can recruit caspase-8, via an interaction between the PYD of ASC and the death effector domain of caspase- $8^{90-92}$. The recruitment of multiple caspases diversifies the signaling and functional repertoire of the NLRC4 inflammasome, providing more ways to orchestrate host responses. Indeed, in response to infection by $S$. Typhimurium, NLRC4 might activate multiple caspasedependent and caspase-independent cell death pathways, including pyroptosis, apoptosis and necroptosis, collectively known as PANoptosis ${ }^{93}$.

\section{$\underline{\text { Host defense against other gastrointestinal pathogens }}$}

In addition to $S$. Typhimurium, NLRC4 defends against infection by several other gastrointestinal pathogens (Table 2) ${ }^{94}$. For example, the Gram-negative bacterium Citrobacter rodentium is a mouse-adapted pathogen used to model the pathogenesis of enteropathogenic Escherichia coli and enterohaemorrhagic E. coli (EHEC) in humans. NLRC4-deficient mice orogastrically infected with C. rodentium sustained severe pathological damage to the cecum and colon, and increased bacterial loads in the cecum ${ }^{79}$. Unlike for 
other pathogens, NLRC4 induces a detrimental outcome in response to infection with the Gram-negative bacterium $H$. pylori, a causative agent of chronic gastritis and stomach cancer. Mice lacking NLRC4 infected with $H$. pylori had lower bacterial loads and reduced neutrophil infiltration to the stomach compared to WT mice ${ }^{95}$. This enhanced resistance to $H$. pylori colonization in mice lacking NLRC4 was thought to be owing to reduced IL-18 secretion, which led to increased expression of the anti-microbial peptide $\beta$-defensin 1 by epithelial cells ${ }^{95}$. The deleterious effect of NLRC4 in the host defense against $H$. pylori is interesting and might reveal new information about the functionality of NLRC4 in the gastric lining. Other reasons for this detrimental effect might be that the NLRC4-dependent cell expulsion mechanism is not functional or effective in gastric cells lining the stomach and/or that production of inflammasome-associated cytokines is generally detrimental in that region of the gastrointestinal tract.

\section{$\underline{\text { Host defense against extra-gastrointestinal pathogens }}$}

Bacteria can colonize and infect anatomical sites other than the gastrointestinal tract of the mammalian host, such as the lungs, skin and eyes. Therefore, host cells in these sites must be able to detect pathogens, including the use the NAIP-NLRC4 inflammasome to respond to bacteria carrying flagellin and/or other NLRC4-activating ligands. The flagellated pneumoniacausing bacterium L. pneumophila infects the lungs and can activate the NAIP-NLRC4 inflammasome (Table 2). Upon nasal infection with L. pneumophila, mice lacking NLRC4 harbored substantially greater bacterial loads in the lungs compared to WT mice ${ }^{96-99}$. Additionally, mice lacking NLRC4 were more permissive to bacterial replication compared to mice lacking both caspase-1 and caspase-11 ${ }^{96}$. These studies suggest that in addition to caspase-1 and caspase-11, NLRC4 might also activate other antimicrobial pathways to confer protection against L. pneumophila. Similar results were also observed for other Legionella species, such as L. micdadei, L. bozemanii, L. gratiana and L. rubrilucens, which all express flagellin ${ }^{98,100}$. These bacteria proliferated unrestricted in mice lacking NLRC4 ${ }^{98,99}$. Further, mice lacking NLRC4 were more susceptible to L. micdadei, L. bozemanii, L. gratiana and $L$. rubrilucens than mice lacking caspase-1 alone ${ }^{97,98}$.

Indeed, NLRC4 can trigger multiple pathways, including activation of apoptotic caspase-7 and caspase-8, phagolysosome maturation, and cell-autonomous immunity 23,91,101-103. To address the role of caspases in the host defense against L. pneumophila infection, caspase-1, caspase-8 and caspase-11 were genetically deleted in mice (Casp1/8/11/Ripk3 ${ }^{-1-}$ mice; note that this mouse strain also carries a genetic deletion of the kinase RIPK3 as it is required to rescue the embryonic lethality of caspase-8 deficiency) ${ }^{96}$. These mice were as susceptible as 
mice lacking NLRC4 in response to L. pneumophila infection ${ }^{96}$. Furthermore, caspase-7 was found to operate downstream of caspase-1/8/11, and that mice lacking caspase- 7 , caspase1 and caspase-11 nasally infected with L. pneumophila were as susceptible as mice lacking NLRC4 ${ }^{96}$. These studies provide additional examples to show that NLRC4 orchestrates activation of multiple inflammatory and apoptotic caspases, allowing the convergence of these pathways to provide effective protection against $L$. pneumophila infection.

Infection of the eye with $P$. aeruginosa, a Gram-negative bacterium encoding flagellin and T3SS, is a frequent cause of microbial keratitis for contact lens users and immunocompromised individuals. The role of NLRC4 in the eye has been investigated using an siRNA approach to knockdown NIrc4 in the cornea of BALB/c mice, followed by an ocular infection with $P$. aeruginosa ${ }^{104}$. The cornea treated with the siRNA against NIrc4 had higher bacterial loads, more severe disease, and reduced neutrophil infiltration compared to the cornea treated with a non-targeting scrambled siRNA ${ }^{104}$. Protein levels of IL-1 $\beta$ and IL-18 were also reduced in the cornea treated with the siRNA against NIrc4 ${ }^{104}$. In an intraperitoneal infection model of $P$. aeruginosa, mice lacking NLRC4 harbored slightly more bacteria in the peritoneal lavage at 12 hours post-infection compared to WT mice ${ }^{105}$. Moreover, mice lacking NLRC4 had substantially less circulating IL-1 $\beta$ and IL-18 compared to WT mice ${ }^{105}$, suggesting an involvement from the NLRC4 inflammasome. In an acute pneumonia model, mice lacking NLRC4 nasally infected with $P$. aeruginosa had an increased bacterial load in the bronchoalveolar lavage, but not in lung tissues, compared to WT mice ${ }^{106}$. Therefore, the biological effect of NLRC4 is largely protective against several bacteria across multiple anatomical sites.

\section{A double-edged sword}

While activation of the NLRC4 inflammasome can elicit an inflammatory response to benefit the host, ensuing inflammation can also cause substantial collateral damage to the host. Indeed, the NLRC4 inflammasome can become 'rogue' if it (1) is no longer effective at controlling bacterial replication/dissemination; and (2) causes sufficient damages in which the survival of the host is threatened. Bacterial infections capable of activating the NLRC4 inflammasome in mice are associated with two systemic symptoms: (1) hypothermia and (2) vascular changes characterized by increased hematocrit, diarrhea and peripheral edema $33,34,76,81,107,108$. These systemic responses are often detrimental and can lead to death of a host. For example, WT mice intravenously infected with a lethal strain of $E$. coli $\mathrm{O} 21: \mathrm{H}+$ were found to have a substantially lower survival rate compared to mice lacking both NAIP5 and NLRC4 ${ }^{107}$. Furthermore, WT mice also suffered severe small intestinal bleeding, multiple 
organ damage, hypothermia and had no additional protective advantage against bacterial dissemination compared to mice lacking both NAIP5 and NLRC4 ${ }^{107 .}$

An experimental approach to trigger systemic activation of the NAIP-NLRC4 inflammasome is to intravenously inject mice with anthrax toxin components protective antigen (PA) along with lethal factor-bound needle (LFn-needle), rod (LFn-rod) or flagellin (LFn-flagellin), such that these NLRC4 ligands are delivered to the cytoplasm of host cells systemically. WT mice undergoing this procedure experienced rapid and substantial reduction in body temperature, elevated hematocrit and diarrhea, and lower survival rate compared to mice lacking NAIP1-6 or NLRC4 ${ }^{33,34,81,108}$.

Additionally, cre-induced flagellin expression to activate the NAIP-NLRC4 inflammasome specifically in myeloid cells caused severe limb swelling at the tibiotarsal joints of WT mice, but not in mice lacking NLRC4 ${ }^{76}$. Severe damage sustained in the tibiotarsal joints, duodenum and the kidneys, and the presentation of leukocytosis can also be observed in these WT mice ${ }^{76}$. Increased vascular permeability that manifests in the form of diarrhea and peripheral edema is a hallmark of NLRC4 activation in mice. Further studies have demonstrated that NLRC4 activation led to a substantial increase in prostanoids production ${ }^{81,108}$. To assess the importance of prostanoids production for hypothermia and vascular changes observed following NLRC4 activation, WT mice and mice lacking cyclooxygenase-1 (COX-1) were treated with PA and LFn-flagellin intraperitoneally ${ }^{108}$. Hypothermia and elevated hematocrit were observed in WT mice but not in mice lacking COX-1 ${ }^{108}$, showing that prostanoids are crucial for the induction of hypothermia and vascular changes following NLRC4 activation. In the context of systemic activation of NLRC4, both hematopoietic-derived and nonhematopoietic-derived cells are probably important for induction of hypothermia and vascular changes ${ }^{108}$. Based on findings from multiple models of infectious disease, it is reasonable to argue that a more localized activation of the NAIP-NLRC4 inflammasome is protective, whereas a systemic and widespread activation may cause substantial harm to the host. This concept is further explored in the context of autoinflammation discussed below.

\section{NLRC4 in autoinflammatory diseases}

Whole exome sequencing techniques have identified novel and de novo mutations in the gene encoding NLRC4 in humans. These mutations are heterozygotic gain-of-function mutations and can lead to autoinflammatory diseases, including early on-set macrophage activation syndrome (MAS), neonatal enterocolitis, fetal thrombotic vasculopathy and familial cold autoinflammatory syndrome (FCAS) (Table 3). 
Patients carrying one of several missense mutations of NLRC4 in the HD1 domain all exhibit autoinflammatory clinical manifestation ${ }^{109-111}$. Studies have found that mutations within this domain may result in a disruption of interactions between the LRRs and NBD, promoting ATP for ADP exchange ${ }^{109}$. These alterations likely allow ligand-independent activation of the NLRC4 inflammasome and thus result in constitutive activation of caspase-1, and secretion of IL-1 $\beta$ and IL-18 ${ }^{109}$. Mechanistically, disruption caused by the mutation, p.Val341Ala, may decrease residue hydrophobicity, reducing interactions in the HD1 domain and similarly promoting ATP for ADP exchange, likely manifesting in the observed cytokine production ${ }^{109}$. Interestingly, a different substitution of leucine at the identical location, p.Val341Leu, led to increased residue hydrophobicity and spontaneous NLRC4 activation evidenced by higher levels of IL-1 $\beta$ and IL-18 in comparison to healthy controls ${ }^{110}$. Both of these gain-of-function mutations have been associated with MAS (Table 3 ).

Disruption in NLRC4 interface interactions has also been reported within the LRRs leading to MAS-like autoinflammation ${ }^{112,113}$. For example, the mutation, p.Trp655Cys, induced a loss of NLRC4 autoinhibition ${ }^{112}$. Transduction of this mutant version of NLRC4 into THP-1 cells led to increased cell death and secretion of IL-1 $\beta$ and IL-18 compared to cells transduced with a WT NLRC4 ${ }^{112}$. This mutant LRRs likely has enhanced interaction with the LRRs of an adjacent NLRC4, promoting NLRC4 oligomerization and increased inflammasome activation. Research into the NLRC4-MAS phenotype has further identified another disease-causing alteration, p.GIn657Leu, in the LRRs ${ }^{113}$. How this mutation affects the activation mechanism of the NLRC4 inflammasome is currently unknown, however the patient displayed elevated IL-18 levels in line with other patients carrying an NLRC4 mutation ${ }^{113}$. These findings demonstrate that mutations occurring in different regions of NLRC4 can manifest in similar autoinflammatory characteristics (such as in MAS), likely via distinct mechanisms.

Gain-of-function mutations have also been observed in the NBD of NLRC4. Many of these mutations have similarly been reported to cause the destabilisation of inactive NLRC4, increasing the propensity of constitutive inflammasome activation and autoinflammation (Table 3). For example, a patient carrying the mutation, p.Thr177Ala, in the NBD had neonatal-onset multisystem inflammatory disease (NOMID) ${ }^{114}$. This alanine substitution, similar to mutations observed in HD1, caused a change in hydrogen bonding, subsequently disrupting ADP-mediated interaction at the WHD-NBD domain, leading to NLRC4 autoactivation ${ }^{114}$. Further, IPSC-derived macrophages from a patient carrying the heterozygous NLRC4 mutation, p.Thr177Ala, produced IL-1 $\beta$ and IL-18 in response to LPS stimulation without a second signal, whereas IPSC-derived macrophages from a patient 
without NLRC4 mutation did not ${ }^{114}$. Mutations in the WHD of NLRC4 have also been associated with autoinflammation ${ }^{115}$, including a case with increased NLRC4-containing inflammasome formation in the absence of a secondary signal ${ }^{116}$. These studies, along with those presented in the HD1 and LRRs, demonstrate that while different molecular mechanisms may lead to overt NLRC4 activation, the inflammasome itself is likely to play a key role in autoinflammatory disease.

Indeed, therapy targeting IL-1 $\beta$ and IL-18 secretion has already shown promise in NLRC4related autoinflammation. The use of $\mathrm{mTOR}$ inhibitor, rapamycin, in the treatment of an infant displaying neonatal MAS, reduced caspase- 1 activation and IL-1 $\beta$ and IL-18 secretion within treated phagocytes, leading to weight gain, reduced cytokine serum levels and overall clinical symptom improvement ${ }^{110}$. Treatment of a similar NLRC4-related case of MAS with a recombinant IL-18 binding protein (rhIL-18BP), to neutralize IL-18, has also shown clinical response ${ }^{117}$. Reduced MAS severity was associated with stabilisation of IL-18 serum levels, hypothesised to occur by inhibition of ongoing IL-18 signaling, demonstrating that therapeutic treatments targeting inflammasome-associated cytokines may be useful in mitigating the effects of NLRC4-related autoinflammation ${ }^{117}$. Currently, no pharmacological inhibitors of NLRC4 have been identified. Drug screening programs accelerating the search for specific inhibitors of NLRC4 would help deliver a more targeted therapy for patients with NLRC4related autoinflammatory diseases. Advances in such treatment, combined with the increased description of mechanisms underpinning inflammasome activation, will help to demystify the role of NLRC4 and improve patient care for those suffering autoinflammatory diseases.

\section{NLRC4 in cancer}

The differential expression of NLRC4 has been observed in a variety of tumor tissue types. Reduced mRNA levels of NLRC4 are evident in the tumor tissues of colorectal cancer ${ }^{118}$. However, more recent studies have demonstrated normal levels in lung tumors ${ }^{119}$ and hepatocellular carcinoma ${ }^{120}$, along with increased expression in breast cancer and glioma 121,122. The role of NLRC4 in tumor regulation and suppression is not always consistent even in the same tumor model (Table 4), as discussed further below.

The role of NLRC4 in colorectal cancer has been investigated in mice intraperitoneally injected with the DNA-damage agent azoxymethane (AOM) and the chemical colitogen dextran sulfate sodium (DSS). This study showed that $\mathrm{NIrC}^{-{ }^{--}}$mice displayed increased tumor formation, reduced apoptosis in tumors and increased proliferation of colonic epithelial cells during the early-stage of the disease compared to WT mice ${ }^{123}$. A similar susceptibility to tumorigenesis was also observed in Casp $1 / 11^{-1-}$ mice ${ }^{123}$, suggesting that the NLRC4 inflammasome is 
mediating protection in this disease context. While these findings suggest that the NLRC4 inflammasome confers protection against colitis-associated tumorigenesis, another study using the same model showed that $\mathrm{NICH}^{-/-}$mice had no increase in hyperplasia and tumor numbers in the colon compared to WT mice, suggesting that NLRC4 has no role in the protection against tumorigenesis ${ }^{124}$. Both studies did not use littermate controls to minimize differences in the gut microbiota profile and/or subtle genetic differences, such as acquired de novo mutations. A later study using littermate controls revealed that $\mathrm{NIrC}^{-/-}$mice were more susceptible to DSS-induced colitis compared to WT mice, potentially owing to reduced production of IL-18 ${ }^{125}$. However, the role of NLRC4 on tumorigenesis, if any, was not investigated.

Regardless of the above findings, the functions of the NLRC4 inflammasome in colitisassociated tumorigenesis might be distinct from how NAIPs function. For example, mice lacking all functional paralogues of NAIPs (called Naip 1-6 $6^{\Delta / \Delta}$ mice) and mice lacking all functional paralogues of NAIPs specifically within the intestinal epithelial cells (called Naip1$6^{\Delta / \Delta I E C}$ mice), had more tumors in the colon following administration of AOM and DSS compared with WT mice ${ }^{35}$. Mice lacking NAIPs did not have impaired inflammasome activation, but instead, had an impaired ability to attenuate hyperactivation of STAT3, a transcription factor which can function to promote tumor growth ${ }^{35}$. Since hyperactivation of STAT3 was not observed in mice lacking NLRC4, these results suggest that the protective effects of NAIPs could be independent of NLRC4 ${ }^{35}$.

The role of NLRC4 in melanoma tumor suppression is also contradictory. $\mathrm{N} / r \mathrm{rC}^{-/-}$mice injected subcutaneously with mouse B16F10 melanoma were initially found to display enhanced tumor growth ${ }^{126}$. The presence of NLRC4 in tumor cells was important in modulating signaling pathways responsible for tumor growth control ${ }^{126}$. Interestingly, $\mathrm{NICC}^{-1-}$ mice also displayed decreased cytokine and chemokine production, such as CXCL9, CXCL10, CXCL16, CCL5, used in T cell recruitment ${ }^{126}$. Similarly, the reduced production of IFN- $\mathrm{\gamma}$ by CD4 ${ }^{+}$and CD8 ${ }^{+} \mathrm{T}$ cells observed in $\mathrm{NIrC4}^{-/-}$mice may contribute to tumor growth ${ }^{126}$. A more recent study using the same model found no role for NLRC4 in melanoma progression, observing no difference in tumor incidence between littermate WT and $\mathrm{NIrC4}^{-l-}$ mice ${ }^{61}$. The use of littermate mice in this study would have largely removed confounding factors such as gut microbiota and subtle genetic differences, arguing for the importance of using littermate controls in future studies. The generation of $\mathrm{NIrC4}^{-1-}$ mice on different substrains of $\mathrm{C} 57 \mathrm{BL} / 6$, such as $\mathrm{C} 57 \mathrm{BL} / 6 \mathrm{~J}$ versus C57BL/6N, may have also contributed to differences in tumor suppression between studies 
126,127. Further studies using littermate controls and mice of an identical genetic background are therefore warranted to demystify the role of NLRC4 in mouse models of cancer.

Research has also expanded into investigating the potential role of NLRC4 in other cancers. NLRC4 and IL-1 $\beta$ have been shown to promote breast tumor progression in diet-induced obese mice ${ }^{128}$. Macrophages were recruited by the obese tumor microenvironment, with activation of the NLRC4 inflammasome in these macrophages promoting the production of adipocyte-originated growth factor vascular endothelial growth factor-A (VEGF-A) and hence angiogenesis ${ }^{128}$. Cell expansion and VEGF-A production were also mediated by NLRC4 in metastases induced by fatty liver disease, similarly driven by IL-1 $\beta$ production ${ }^{129}$. Indeed, these mouse studies are supported by data from a cohort of human patients with breast cancer, showing that patients with higher levels of NLRC4 mRNA transcripts have a poorer survival rate ${ }^{128}$. These survival plots extend to glioma patients, demonstrating a similar relationship between higher NLRC4 expression and poor prognosis ${ }^{130}$. The study also confirmed increased IL-1 $\beta$ expression in glioma patients with a poorer outcome ${ }^{130}$, implicating a role of IL-1 $\beta$ secretion in driving glioma progression. Further studies are therefore required to investigate the tentative link between NLRC4-mediated IL-1 $\beta$ secretion and tumor progression, potentially positioning the NLRC4-IL-1 $\beta$ pathway as a potential therapeutic target for inhibition in glioma and other cancers.

\section{Conclusions and Future Directions}

Despite unprecedented insights into the structure and activation mechanisms of the NAIPNLRC4 inflammasome, limitations in our knowledge still exist. In the context of infectious diseases, NAIP-NLRC4 exploits the structural and functional conservation of virulence factors encoded by many pathogenic bacteria, such as $S$. Typhimurium and $P$. aeruginosa. A single human NAIP and its isoforms recognize multiple bacterial ligands whereas at least 4 mouse NAIPs are required to do so. How is human NAIP able to bind multiple ligands? Would human NAIP require additional upstream sensors? Answers to these questions would open new lines of enquiry in the field of innate immune recognition. Evidence that NLRC4 can induce sterile inflammation in the brain might even suggest that it can sense endogenous danger signals. Further, the role of the remaining murine NAIPs 3, 4 and 7 in NLRC4 inflammasome activation remains unexplored. Given that the C57BL/6 mice only express NAIPs 1, 2, 5 and 6, the function of the remaining murine NAIPs will likely require interrogation using mouse strains of other genetic background. 
NAIP-NLRC4 activates multiple pathways to limit bacterial replication and dissemination, including secretion of IL-1 $\beta$ and IL-18, pyroptosis, and expulsion of infected cells from the host. So far, an association between loss-of-function mutations in either NAIP or NLRC4 and susceptibility to infections in humans has not been reported. Mice lacking NLRC4 do not readily succumb to infection in a specific-pathogen-free environment, suggesting that deficiency of NLRC4 in mice does not lead to hypersusceptibility to host or environmental microbiota. Further, some mammalian species, such as pigs, lack functional NLRC4 and NAIPs ${ }^{131}$. NAIP-NLRC4 might provide protection against certain bacterial pathogens in mice, but overt activation of NAIP-NLRC4 induces systemic inflammation, sepsis and death in humans and mice. Therefore, the evolutionary advantage of encoding NAIP-NLRC4, against a backdrop of inherent risk of triggering overt inflammation, probably extends beyond protection against bacterial infection.

Indeed, emerging studies have shown that NLRC4 is differentially expressed in some tumour tissues compared with healthy tissues. Although no consensus on the role of NAIPs or NLRC4 using mouse models of cancer has been made, the recognized needs to use littermate controls in these experiments will increase the consistency and reproducibility of studies in the future. Further, the emerging inflammasome-independent roles of NAIPs or NLRC4 in tumorigenesis are exciting because these mechanistic insights would identify novel pathwaytargets to be used in the development of immunotherapies.

In autoinflammatory conditions linked to gain-of-function mutations of NLRC4, progress has been made in translating fundamental discoveries to clinical practice. Patients with MAS have been successfully treated by targeting cytokines produced as a result of constitutive activation of the NLRC4 inflammasome. An important consideration is the consequences of sustained inhibition of inflammasome-associated cytokines in patients, given that these cytokines are critical for the control of infection. Would these complications be minimized if NLRC4 is specifically inhibited instead? Unfortunately, no pharmacological inhibitors of NLRC4 have been discovered. Identifying safe and efficacious compounds that specifically inhibit NLRC4 would provide a more targeted therapy for these patients. Future studies will yield insights into the role of NAIP-NLRC4 in clinical manifestations beyond infectious diseases and identify pharmacologic compounds and host targets to accelerate the development of therapies to improve patient care. 


\section{ACKNOWLEDGEMENTS}

S.M.M. is supported by the Australian National University, and the National Health and Medical Research Council of Australia under Project Grants APP1141504, APP1146864, APP1162103, and APP1163358, and the R.D. Wright Career Development Fellowship APP1162025. M.K. is supported by a Tuckwell Scholarship from the Australian National University.

\section{CONFLICT OF INTEREST}

The authors have no conflict of interest to declare.

\section{$\underline{\text { ORCID }}$}

\section{Callum Kay}

https://orcid.org/0000-0002-0985-6206

\section{Runli Wang}

https://orcid.org/0000-0002-5361-3316

Max Kirkby

https://orcid.org/0000-0003-2424-1047

\section{Si Ming Man}

https://orcid.org/0000-0002-5079-2857 
Table 1. Investigations into the roles of NLRC4 and NAIPs in salmonellosis using mouse models.

\begin{tabular}{|c|c|c|c|c|c|}
\hline Mouse & $\begin{array}{l}\text { Infection } \\
\text { route }\end{array}$ & $\begin{array}{c}\text { Genetic } \\
\text { background }\end{array}$ & Littermate & $\begin{array}{l}\text { Phenotype compared to } \\
\text { wildtype mice (unless } \\
\text { stated otherwise) }\end{array}$ & Reference \\
\hline \multirow[t]{11}{*}{ NIrc4 ${ }^{-1-}$} & Orogastric & C57BL/6 & Yes & $\begin{array}{l}\text { No difference in bacterial } \\
\text { burden in the spleen and } \\
\text { mesenteric lymph nodes 5- } \\
\text { days post infection }\end{array}$ & 86 \\
\hline & & C57BL/6N & No & $\begin{array}{l}\text { No difference in bacterial } \\
\text { burden in the spleen, liver } \\
\text { and mesenteric lymph } \\
\text { nodes } 5 \text {-days post infection }\end{array}$ & 59 \\
\hline & & $\mathrm{BALB} / \mathrm{c}$ & No & $\begin{array}{l}\text { Decreased survival rate } \\
\text { Increased bacterial burden } \\
\text { in the liver and spleen }\end{array}$ & 87 \\
\hline & & $\begin{array}{l}\text { C57BL/6 } \\
\text { Charles } \\
\text { River }\end{array}$ & Yes & $\begin{array}{l}\text { Increased epithelial } \\
\text { invasion 18-hrs post } \\
\text { infection, compared with } \\
\text { heterozygous } N I r c 4^{+/} \text {mice }\end{array}$ & 80 \\
\hline & & C57BL/6J & Yes & $\begin{array}{l}\text { Increased bacterial burden } \\
\text { in the cecal tissues 18-hrs } \\
\text { post infection }\end{array}$ & 81 \\
\hline & & C57BL/6J & Yes & $\begin{array}{l}\text { Increased bacterial burden } \\
\text { in the cecum and } \\
\text { mesenteric lymph nodes } \\
\text { 18-hrs post infection, } \\
\text { compared with } \\
\text { heterozygous } \mathrm{NIrC4}^{+/-} \text {mice }\end{array}$ & 61 \\
\hline & $\begin{array}{l}\text { Intraperitone } \\
\text { al }\end{array}$ & $\mathrm{BALB} / \mathrm{c}$ & No & $\begin{array}{l}\text { No difference in survival } \\
\text { rate } \\
\text { No difference in bacterial } \\
\text { burden in the liver and } \\
\text { spleen 3-days post } \\
\text { infection }\end{array}$ & 87 \\
\hline & & C57BL/6 & No & $\begin{array}{l}\text { Increased bacterial burden } \\
\text { in the spleen and liver 7- } \\
\text { and 13-days post infection }\end{array}$ & 60 \\
\hline & & C57BL/6 & No & Decreased survival rate & 34 \\
\hline & & C57BL/6J & No & $\begin{array}{l}\text { Decreased survival rate } \\
\text { Increased bacterial burden } \\
\text { in the spleen and liver } \\
\text { Reduced IL-18 in the } \\
\text { spleen and liver }\end{array}$ & 64 \\
\hline & Intravenous & C57BL/6NJ & Yes & $\begin{array}{l}\text { No difference in bacterial } \\
\text { burden in the spleen and } \\
\text { mesenteric lymph nodes } \\
\text { 24-hrs post infection }\end{array}$ & 80 \\
\hline
\end{tabular}




\begin{tabular}{|c|c|c|c|c|c|}
\hline Naip2-I- & $\begin{array}{c}\text { Intraperitone } \\
\text { al }\end{array}$ & C57BL/6 & No & $\begin{array}{l}\text { Decreased survival rate } \\
\text { No difference in bacterial } \\
\text { burden in the spleen and } \\
\text { liver }\end{array}$ & 34 \\
\hline \multirow[t]{2}{*}{ Naip5-1- } & $\begin{array}{l}\text { Intraperitone } \\
\text { al }\end{array}$ & C57BL/6 & No & $\begin{array}{l}\text { Decreased survival rate } \\
\text { No difference in bacterial } \\
\text { burden in the spleen and } \\
\text { liver }\end{array}$ & 34 \\
\hline & & C57BL/6 & No & $\begin{array}{l}\text { No difference in survival } \\
\text { rate } \\
\text { No difference in bacterial } \\
\text { burden in the spleen and } \\
\text { liver } \\
\text { No difference in IL-18 in the } \\
\text { spleen and liver }\end{array}$ & 64 \\
\hline$\underset{I \Delta}{N^{N a i p 1-6}}$ & Orogastric & $\begin{array}{c}\text { C57BL/6 } \\
\text { Charles } \\
\text { River }\end{array}$ & Yes & $\begin{array}{l}\text { Increased histopathology } \\
\text { score } \\
\text { Increased bacterial burden } \\
\text { in both the cecum and } \\
\text { mesenteric lymph nodes } \\
\text { 18- and 36-hrs post } \\
\text { infection, compared with } \\
\text { heterozygous Naip 1-6 f// } \\
\text { mice }\end{array}$ & 80 \\
\hline
\end{tabular}


Table 2. The role of NLRC4 in the host defense against bacteria other than S. Typhimurium using mouse models.

\begin{tabular}{|c|c|c|c|c|c|c|}
\hline Mouse & $\begin{array}{l}\text { Infection } \\
\text { route }\end{array}$ & Bacteria & $\begin{array}{c}\text { Genetic } \\
\text { background }\end{array}$ & Littermate & $\begin{array}{l}\text { Phenotype compared to } \\
\text { wildtype mice (unless stated } \\
\text { otherwise) }\end{array}$ & Reference \\
\hline \multirow[t]{10}{*}{ NIrc4-1- } & Orogastric & C. rodentium & C57BL/6 & No & $\begin{array}{l}\text { Increased bacterial burden in } \\
\text { the cecum } 8 \text { - and 14-days post } \\
\text { infection } \\
\text { Increased pathological score in } \\
\text { the colon and cecum }\end{array}$ & 79 \\
\hline & & H. pylori & C57BL/6N & Yes & $\begin{array}{l}\text { Reduced bacterial burden in the } \\
\text { stomach } 1 \text {-month post infection } \\
\text { Reduced IL-18 secretion and } \\
\text { neutrophil recruitment to the } \\
\text { stomach }\end{array}$ & 95 \\
\hline & Nasal & $\begin{array}{c}L . \\
\text { pneumophila }\end{array}$ & C57BL/6 & Yes & $\begin{array}{l}\text { Increased bacterial burden in } \\
\text { the lung 48- and 96-hrs post } \\
\text { infection }\end{array}$ & 97 \\
\hline & & & C57BL/6J & No & $\begin{array}{l}\text { Increased bacterial burden in } \\
\text { the lung } 48-\text { and } 72 \text {-hrs post } \\
\text { infection }\end{array}$ & 96 \\
\hline & & L. micdadei & C57BL/6 & Yes & $\begin{array}{l}\text { Increased bacterial burden in } \\
\text { the lung } 48 \text { - and } 72 \text {-hrs post } \\
\text { infection }\end{array}$ & 99 \\
\hline & & L. bozemanii & C57BL/6 & Yes & $\begin{array}{l}\text { Increased bacterial burden in } \\
\text { the lung } 48-\text { and } 72-\text { hrs post } \\
\text { infection }\end{array}$ & 99 \\
\hline & & L. gratiana & C57BL/6 & Yes & $\begin{array}{l}\text { Increased bacterial burden in } \\
\text { the lung } 48-\text { and } 72-\text { hrs post } \\
\text { infection }\end{array}$ & 97,99 \\
\hline & & $\begin{array}{l}L . \\
\text { rubrilucens }\end{array}$ & C57BL/6 & Yes & $\begin{array}{l}\text { Increased bacterial burden in } \\
\text { the lung } 48-\text { and } 72-\text { hrs post } \\
\text { infection }\end{array}$ & 99 \\
\hline & & $\begin{array}{c}P . \\
\text { aeruginosa }\end{array}$ & C57BL/6 & No & $\begin{array}{l}\text { Increased bacterial burden in } \\
\text { the bronchoalveolar lavage 18- } \\
\text { hrs post infection }\end{array}$ & 106 \\
\hline & $\begin{array}{c}\text { Intraperiton } \\
\text { eal }\end{array}$ & $\begin{array}{c}P . \\
\text { aeruginosa }\end{array}$ & C57BL/6J & Yes & $\begin{array}{l}\text { Increased bacterial burden in } \\
\text { the peritoneal lavage 12-hrs } \\
\text { post infection } \\
\text { Reduced circulating IL-1D and } \\
\text { IL-18 }\end{array}$ & 105 \\
\hline $\begin{array}{l}\text { NIrc4 } \\
\text { siRNA } \\
\text { knockdo } \\
\text { wn }\end{array}$ & Ocular & $\begin{array}{c}P . \\
\text { aeruginosa }\end{array}$ & BALB/c & $\mathrm{N} / \mathrm{A}$ & $\begin{array}{l}\text { Increased bacterial burden in } \\
\text { the cornea 5-days post infection } \\
\text { Severe pathological scoring } \\
\text { Reduced neutrophil infiltration }\end{array}$ & 104 \\
\hline
\end{tabular}


Table 3. List of known NLRC4 mutations linked to an autoinflammatory phenotype.

\begin{tabular}{|c|c|c|c|c|c|}
\hline Nucleotide & Amino Acid & $\begin{array}{l}\text { NLRC4 } \\
\text { domain }\end{array}$ & $\begin{array}{l}\text { Predicted } \\
\text { type of } \\
\text { mutation }\end{array}$ & $\begin{array}{l}\text { Resulting } \\
\text { phenotype }\end{array}$ & Reference \\
\hline c. $512 \mathrm{C}>\mathrm{T}$ & p.Ser171Phe & NBD & $\begin{array}{l}\text { Gain-of- } \\
\text { function }\end{array}$ & $\begin{array}{l}\text { Perinatal } \\
\text { autoinflammation } \\
\text { with MAS-HLH and } \\
\text { fetal thrombotic } \\
\text { vasculopathy. }\end{array}$ & 132 \\
\hline c. $529 A>G$ & p.Thr177Ala & NBD & Unknown & $\begin{array}{l}\text { Neonatal-onset } \\
\text { multisystem } \\
\text { inflammatory } \\
\text { disease (NOMID). }\end{array}$ & 114 \\
\hline $\begin{array}{c}\text { c. } 1009 A> \\
T\end{array}$ & p.Thr337Ser & HD1 & $\begin{array}{l}\text { Gain-of- } \\
\text { function }\end{array}$ & $\begin{array}{l}\text { Consistent } \\
\text { autoinflammation } \\
\text { with recurrent MAS- } \\
\text { HLH in European } \\
\text { child. }\end{array}$ & 111 \\
\hline $\begin{array}{c}\text { c.1021G > } \\
\text { C }\end{array}$ & p.Val341Leu & HD1 & $\begin{array}{l}\text { Gain-of- } \\
\text { function }\end{array}$ & $\begin{array}{l}\text { Neonatal MAS in } \\
\text { male infant. }\end{array}$ & 110 \\
\hline $\begin{array}{c}\text { c. } 1022 T> \\
\text { C }\end{array}$ & p.Val341Ala & HD1 & $\begin{array}{l}\text { Gain-of- } \\
\text { function }\end{array}$ & $\begin{array}{l}\text { (1) Neonatal-onset } \\
\text { enterocolitis, } \\
\text { episodes of } \\
\text { autoinflammation } \\
\text { in a family in the } \\
\text { USA. } \\
\text { (2) Infant with } \\
\text { severe, } \\
\text { refractory MAS. }\end{array}$ & $\begin{array}{l}\text { (1) } 109 \\
\text { (2) } 117\end{array}$ \\
\hline c. $1333 T>C$ & p.Ser445Pro & WHD & Unknown & $\begin{array}{l}\text { Cutaneous } \\
\text { erythematous nodes } \\
\text { and urticarial rash, } \\
\text { arthralgias, and late- } \\
\text { onset enterocolitis in } \\
\text { sample of } 13 \\
\text { patients. }\end{array}$ & 115 \\
\hline $\begin{array}{c}\text { c.1589A > } \\
\text { C }\end{array}$ & p.His443Pro & WHD & $\begin{array}{l}\text { Gain-of- } \\
\text { function }\end{array}$ & $\begin{array}{l}\text { FCAS in a family in } \\
\text { Japan. }\end{array}$ & 116 \\
\hline $\begin{array}{c}\text { c. } 1965 G> \\
C\end{array}$ & p.Trp655Cys & LRR & $\begin{array}{l}\text { Gain-of- } \\
\text { function }\end{array}$ & $\begin{array}{l}\text { Early-onset MAS in } \\
2 \text { patients. }\end{array}$ & 112 \\
\hline $\begin{array}{c}\text { c. } 1970 A> \\
T\end{array}$ & p.GIn657Leu & LRR & $\begin{array}{l}\text { Gain-of- } \\
\text { function }\end{array}$ & $\begin{array}{l}\text { Recurrent fever, } \\
\text { skinerythema, and } \\
\text { inflammatory } \\
\text { arthritis in 12-year- } \\
\text { old Malay girl. }\end{array}$ & 113 \\
\hline
\end{tabular}

Abbreviations: FCAS, familial cold autoinflammatory syndrome; HD1, helical domain 1; HLH, hemophagocytic lymphohistiocytosis; LRR, leucine-rich repeat domain; MAS, macrophage activation syndrome; NBD, nucleotide binding domain; WHD, winged-helix domain. 
Table 4. Investigation into the role of NLRC4 and NAIPs in cancer using mouse models.

\begin{tabular}{|c|c|c|c|c|c|}
\hline $\begin{array}{l}\text { Cancer } \\
\text { model }\end{array}$ & Mouse & $\begin{array}{c}\text { Genetic } \\
\text { background }\end{array}$ & Littermate & $\begin{array}{c}\text { Phenotype compared to } \\
\text { wildtype mice }\end{array}$ & Reference \\
\hline \multirow[t]{5}{*}{$\begin{array}{l}\text { Colorect } \\
\text { al } \\
\text { (induced } \\
\text { by AOM } \\
+ \text { DSS) }\end{array}$} & NIrc4 ${ }^{-l-}$ & C57BL/6 & No & $\begin{array}{ll}\text { - } & \text { Increased tumor } \\
\text { formation } \\
\text { - } & \text { Reduced apoptosis } \\
\text { within tumours } \\
\text { - Increased proliferation } \\
\text { of colonic epithelial cells }\end{array}$ & 123 \\
\hline & NIrc4 $4^{-1-}$ & C57BL/6 & No & $\begin{array}{l}\text { No increase in } \\
\text { hyperplasia or tumor } \\
\text { numbers within the } \\
\text { colon }\end{array}$ & 124 \\
\hline & $\begin{array}{l}\text { Naip1- } \\
6^{\Delta / \Delta}\end{array}$ & C57BL/6 & No & $\begin{array}{l}\text { - Increased tumors within } \\
\text { colon compared to } \\
\text { nonlittermate Naip 1-6f/ffl } \\
\text { mice } \\
\text { - Impaired ability to } \\
\text { attenuate STAT3 } \\
\text { hyperactivation }\end{array}$ & 35 \\
\hline & $\begin{array}{l}\text { Naip1- } \\
6^{\Delta / \Delta I E C}\end{array}$ & C57BL/6 & Yes & $\begin{array}{l}\text { - Increased tumors within } \\
\text { colon compared to } \\
\text { littermate Naip1-6/f/l } \\
\text { mice } \\
\text { - Impaired ability to } \\
\text { attenuate STAT3 } \\
\text { hyperactivation }\end{array}$ & 35 \\
\hline & $\begin{array}{l}\text { Naip1- } \\
6^{\Delta / \Delta L y s M}\end{array}$ & C57BL/6 & Yes & $\begin{array}{l}\text { Similar tumor burden } \\
\text { compared to littermate } \\
\text { Naip } 1-6^{f / f l} \text { mice }\end{array}$ & 35 \\
\hline $\begin{array}{l}\text { Colorect } \\
\text { al } \\
\text { (induced } \\
\text { by AOM } \\
\text { only) }\end{array}$ & $\begin{array}{l}\text { Naip1- } \\
6^{\Delta / \Delta}\end{array}$ & C57BL/6 & No & $\begin{array}{l}\text { Increased tumors within } \\
\text { colon compared to } \\
\text { nonlittermate Naip 1-6f/ffl } \\
\text { mice }\end{array}$ & 35 \\
\hline \multirow{2}{*}{$\begin{array}{l}\text { Melanom } \\
\text { a } \\
\text { (transpla } \\
\text { nted with } \\
\text { B16F10 } \\
\text { cells) }\end{array}$} & NIrc4 ${ }^{-I-}$ & C57BL/6N & No & $\begin{array}{l}\text { Enhanced tumor growth } \\
\text { - Decreased cytokine and } \\
\text { chemokine production }\end{array}$ & 126 \\
\hline & NIrc4 $4^{-I-}$ & C57BL/6J & Yes & $\begin{array}{l}\text { - No difference in tumor } \\
\text { incidence when } \\
\text { compared to littermate } \\
\text { WT mice }\end{array}$ & 61 \\
\hline $\begin{array}{c}\text { Breast } \\
\text { (transpla } \\
\text { nted with } \\
\text { Py8119 } \\
\text { cells or } \\
\text { E0771 } \\
\text { cells) }\end{array}$ & NIrc4 $4^{-/-}$ & C57BL/6N & No & 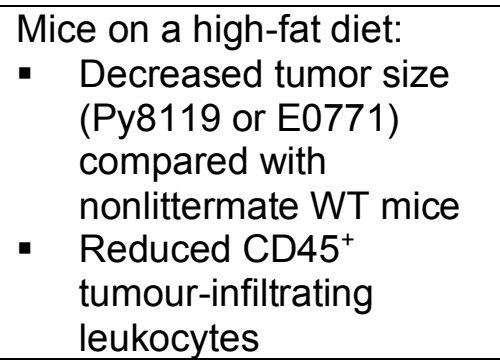 & 128 \\
\hline
\end{tabular}


- Reduced angiogenesis and VEGF-A production

On a normal diet:

- Decreased tumor size (E0771 only) compared with nonlittermate WT mice

Abbreviations: AOM, azoxymethane; DSS, Dextran Sodium Sulfate; VEGF-A, Vascular endothelial growth factor-A. 


\section{References:}

1. Martinon F, Burns K, Tschopp J. The inflammasome: a molecular platform triggering activation of inflammatory caspases and processing of prolL-beta. Mol Cell. 2002;10(2):417-426.

2. Liston A, Masters SL. Homeostasis-altering molecular processes as mechanisms of inflammasome activation. Nat Rev Immunol. 2017;17(3):208-214.

3. Xue Y, Enosi Tuipulotu D, Tan WH, Kay C, Man SM. Emerging Activators and Regulators of Inflammasomes and Pyroptosis. Trends Immunol. 2019;40(11):10351052.

4. Man SM, Kanneganti TD. Regulation of inflammasome activation. Immunol Rev. 2015;265(1):6-21.

5. Broz P, Dixit VM. Inflammasomes: mechanism of assembly, regulation and signalling. Nat Rev Immunol. 2016;16(7):407-420.

6. Rathinam VA, Fitzgerald KA. Inflammasome Complexes: Emerging Mechanisms and Effector Functions. Cell. 2016;165(4):792-800.

7. Franklin BS, Latz E, Schmidt FI. The intra- and extracellular functions of ASC specks. Immunol Rev. 2018;281(1):74-87.

8. Kayagaki $\mathrm{N}$, Warming S, Lamkanfi $\mathrm{M}$, et al. Non-canonical inflammasome activation targets caspase-11. Nature. 2011;479(7371):117-121.

9. Hagar JA, Powell DA, Aachoui Y, Ernst RK, Miao EA. Cytoplasmic LPS activates caspase-11: implications in TLR4-independent endotoxic shock. Science. 2013;341(6151):1250-1253.

10. Shi J, Zhao Y, Wang Y, et al. Inflammatory caspases are innate immune receptors for intracellular LPS. Nature. 2014;514(7521):187-192.

11. Stowe I, Lee B, Kayagaki N. Caspase-11: arming the guards against bacterial infection. Immunol Rev. 2015;265(1):75-84.

12. Man SM, Karki R, Kanneganti TD. Molecular mechanisms and functions of pyroptosis, inflammatory caspases and inflammasomes in infectious diseases. Immunol Rev. 2017;277(1):61-75.

13. Shi J, Zhao Y, Wang $K$, et al. Cleavage of GSDMD by inflammatory caspases determines pyroptotic cell death. Nature. 2015;526(7575):660-665.

14. Kayagaki N, Stowe IB, Lee BL, et al. Caspase-11 cleaves gasdermin D for noncanonical inflammasome signalling. Nature. 2015;526(7575):666-671.

15. He WT, Wan H, Hu L, et al. Gasdermin D is an executor of pyroptosis and required for interleukin-1beta secretion. Cell Res. 2015;25(12):1285-1298.

16. Ding J, Wang K, Liu W, et al. Pore-forming activity and structural autoinhibition of the gasdermin family. Nature. 2016;535(7610):111-116.

17. Liu X, Zhang Z, Ruan J, et al. Inflammasome-activated gasdermin D causes pyroptosis by forming membrane pores. Nature. 2016;535(7610):153-158.

18. Poyet JL, Srinivasula SM, Tnani M, Razmara M, Fernandes-Alnemri T, Alnemri ES. Identification of Ipaf, a human caspase-1-activating protein related to Apaf-1. J Biol Chem. 2001;276(30):28309-28313.

19. Ting JP, Lovering RC, Alnemri ES, et al. The NLR gene family: a standard nomenclature. Immunity. 2008;28(3):285-287. 
20. Mariathasan S, Newton K, Monack DM, et al. Differential activation of the inflammasome by caspase-1 adaptors ASC and Ipaf. Nature. 2004;430(6996):213218.

21. Franchi L, Amer A, Body-Malapel M, et al. Cytosolic flagellin requires Ipaf for activation of caspase-1 and interleukin 1beta in salmonella-infected macrophages. Nat Immunol. 2006;7(6):576-582.

22. Miao EA, Alpuche-Aranda CM, Dors M, et al. Cytoplasmic flagellin activates caspase1 and secretion of interleukin 1beta via Ipaf. Nat Immunol. 2006;7(6):569-575.

23. Amer A, Franchi L, Kanneganti TD, et al. Regulation of Legionella phagosome maturation and infection through flagellin and host Ipaf. J Biol Chem. 2006;281(46):35217-35223.

24. Hayashi F, Smith KD, Ozinsky A, et al. The innate immune response to bacterial flagellin is mediated by Toll-like receptor 5. Nature. 2001;410(6832):1099-1103.

25. Miao EA, Mao DP, Yudkovsky N, et al. Innate immune detection of the type III secretion apparatus through the NLRC4 inflammasome. Proc Natl Acad Sci U S A. 2010;107(7):3076-3080.

26. Damiano JS, Oliveira V, Welsh K, Reed JC. Heterotypic interactions among NACHT domains: implications for regulation of innate immune responses. Biochem J. 2004;381(Pt 1):213-219.

27. Lightfield KL, Persson J, Brubaker SW, et al. Critical function for Naip5 in inflammasome activation by a conserved carboxy-terminal domain of flagellin. Nat Immunol. 2008;9(10):1171-1178.

28. Lightfield KL, Persson J, Trinidad NJ, et al. Differential requirements for NAIP5 in activation of the NLRC4 inflammasome. Infect Immun. 2011;79(4):1606-1614.

29. Zhao Y, Yang J, Shi J, et al. The NLRC4 inflammasome receptors for bacterial flagellin and type III secretion apparatus. Nature. 2011;477(7366):596-600.

30. Kofoed EM, Vance RE. Innate immune recognition of bacterial ligands by NAIPs determines inflammasome specificity. Nature. 2011;477(7366):592-595.

31. Rayamajhi M, Zak DE, Chavarria-Smith J, Vance RE, Miao EA. Cutting edge: Mouse NAIP1 detects the type III secretion system needle protein. J Immunol. 2013;191(8):3986-3989.

32. Yang J, Zhao Y, Shi J, Shao F. Human NAIP and mouse NAIP1 recognize bacterial type III secretion needle protein for inflammasome activation. Proc Natl Acad Sci U SA. 2013;110(35):14408-14413.

33. Rauch I, Tenthorey JL, Nichols RD, et al. NAIP proteins are required for cytosolic detection of specific bacterial ligands in vivo. J Exp Med. 2016;213(5):657-665.

34. Zhao Y, Shi J, Shi X, Wang Y, Wang F, Shao F. Genetic functions of the NAIP family of inflammasome receptors for bacterial ligands in mice. J Exp Med. 2016;213(5):647656.

35. Allam R, Maillard MH, Tardivel A, et al. Epithelial NAIPs protect against colonic tumorigenesis. J Exp Med. 2015;212(3):369-383.

36. Endrizzi MG, Hadinoto V, Growney JD, Miller W, Dietrich WF. Genomic sequence analysis of the mouse Naip gene array. Genome Res. 2000;10(8):1095-1102.

37. Kortmann J, Brubaker SW, Monack DM. Cutting Edge: Inflammasome Activation in Primary Human Macrophages Is Dependent on Flagellin. J Immunol. 2015;195(3):815-819. 
38. Reyes Ruiz VM, Ramirez J, Naseer N, et al. Broad detection of bacterial type III secretion system and flagellin proteins by the human NAIP/NLRC4 inflammasome. Proc Natl Acad Sci U S A. 2017;114(50):13242-13247.

39. Latz E, Xiao TS, Stutz A. Activation and regulation of the inflammasomes. Nat Rev Immunol. 2013;13(6):397-411.

40. Mathur A, Hayward JA, Man SM. Molecular mechanisms of inflammasome signaling. J Leukoc Biol. 2018;103(2):233-257.

41. Zhang L, Chen S, Ruan J, et al. Cryo-EM structure of the activated NAIP2-NLRC4 inflammasome reveals nucleated polymerization. Science. 2015;350(6259):404-409.

42. Hu Z, Zhou Q, Zhang $C$, et al. Structural and biochemical basis for induced selfpropagation of NLRC4. Science. 2015;350(6259):399-404.

43. Tenthorey JL, Haloupek N, Lopez-Blanco JR, et al. The structural basis of flagellin detection by NAIP5: A strategy to limit pathogen immune evasion. Science. 2017;358(6365):888-893.

44. Smith KD, Andersen-Nissen E, Hayashi F, et al. Toll-like receptor 5 recognizes a conserved site on flagellin required for protofilament formation and bacterial motility. Nat Immunol. 2003;4(12):1247-1253.

45. Danot O, Marquenet E, Vidal-Ingigliardi D, Richet E. Wheel of Life, Wheel of Death: A Mechanistic Insight into Signaling by STAND Proteins. Structure. 2009;17(2):172-182.

46. Song DH, Lee JO. Sensing of microbial molecular patterns by Toll-like receptors. Immunol Rev. 2012;250(1):216-229.

47. Tenthorey JL, Kofoed EM, Daugherty MD, Malik HS, Vance RE. Molecular basis for specific recognition of bacterial ligands by NAIP/NLRC4 inflammasomes. Mol Cell. 2014;54(1):17-29.

48. Hu Z, Yan C, Liu P, et al. Crystal structure of NLRC4 reveals its autoinhibition mechanism. Science. 2013;341(6142):172-175.

49. Acehan D, Jiang X, Morgan DG, Heuser JE, Wang X, Akey CW. Three-dimensional structure of the apoptosome: implications for assembly, procaspase- 9 binding, and activation. Mol Cell. 2002;9(2):423-432.

50. Duncan JA, Canna SW. The NLRC4 Inflammasome. Immunol Rev. 2018;281(1):115123.

51. Zhao Y, Shao F. The NAIP-NLRC4 inflammasome in innate immune detection of bacterial flagellin and type III secretion apparatus. Immunol Rev. 2015;265(1):85102.

52. Vance RE. The NAIP/NLRC4 inflammasomes. Curr Opin Immunol. 2015;32:84-89.

53. Hayward JA, Mathur A, Ngo C, Man SM. Cytosolic Recognition of Microbes and Pathogens: Inflammasomes in Action. Microbiol Mol Biol Rev. 2018;82(4).

54. Qu Y, Misaghi S, Izrael-Tomasevic A, et al. Phosphorylation of NLRC4 is critical for inflammasome activation. Nature. 2012;490(7421):539-542.

55. Suzuki S, Franchi L, He Y, et al. Shigella type III secretion protein Mxil is recognized by Naip2 to induce NIrc4 inflammasome activation independently of Pkcdelta. PLoS Pathog. 2014;10(2):e1003926.

56. Liu W, Liu X, Li Y, et al. LRRK2 promotes the activation of NLRC4 inflammasome during Salmonella Typhimurium infection. J Exp Med. 2017;214(10):3051-3066.

57. Matusiak M, Van Opdenbosch N, Vande Walle L, Sirard JC, Kanneganti TD, Lamkanfi M. Flagellin-induced NLRC4 phosphorylation primes the inflammasome for activation by NAIP5. Proc Natl Acad Sci U S A. 2015;112(5):1541-1546. 
58. Qu Y, Misaghi S, Newton K, et al. NLRP3 recruitment by NLRC4 during Salmonella infection. J Exp Med. 2016;213(6):877-885.

59. Broz P, Newton K, Lamkanfi M, Mariathasan S, Dixit VM, Monack DM. Redundant roles for inflammasome receptors NLRP3 and NLRC4 in host defense against Salmonella. J Exp Med. 2010;207(8):1745-1755.

60. Man SM, Hopkins $\amalg$, Nugent E, et al. Inflammasome activation causes dual recruitment of NLRC4 and NLRP3 to the same macromolecular complex. Proc Natl Acad Sci U S A. 2014;111(20):7403-7408.

61. Tenthorey JL, Chavez RA, Thompson TW, Deets KA, Vance RE, Rauch I. NLRC4 inflammasome activation is NLRP3- and phosphorylation-independent during infection and does not protect from melanoma. J Exp Med. 2020;217(7).

62. Kumar Y, Radha V, Swarup G. Interaction with Sug1 enables Ipaf ubiquitination leading to caspase 8 activation and cell death. Biochem J. 2010;427(1):91-104.

63. Raghawan AK, Sripada A, Gopinath G, et al. A Disease-associated Mutant of NLRC4 Shows Enhanced Interaction with SUG1 Leading to Constitutive FADD-dependent Caspase-8 Activation and Cell Death. J Biol Chem. 2017;292(4):1218-1230.

64. Karki R, Lee E, Place D, et al. IRF8 Regulates Transcription of Naips for NLRC4 Inflammasome Activation. Cell. 2018;173(4):920-933 e913.

65. Yamagata $T$, Nishida J, Tanaka S, et al. A novel interferon regulatory factor family transcription factor, ICSAT/Pip/LSIRF, that negatively regulates the activity of interferon-regulated genes. Mol Cell Biol. 1996;16(4):1283-1294.

66. Carpentier SJ, Ni M, Duggan JM, James RG, Cookson BT, Hamerman JA. The signaling adaptor BCAP inhibits NLRP3 and NLRC4 inflammasome activation in macrophages through interactions with Flightless-1. Sci Signal. 2019;12(581).

67. Raghawan AK, Ramaswamy R, Radha V, Swarup G. HSC70 regulates cold-induced caspase- 1 hyperactivation by an autoinflammation-causing mutant of cytoplasmic immune receptor NLRC4. Proc Natl Acad Sci U S A. 2019;116(43):21694-21703.

68. Hu GQ, Song PX, Chen W, et al. Cirtical role for Salmonella effector SopB in regulating inflammasome activation. Mol Immunol. 2017;90:280-286.

69. Wang X, Shaw DK, Sakhon OS, et al. The Tick Protein Sialostatin L2 Binds to Annexin A2 and Inhibits NLRC4-Mediated Inflammasome Activation. Infect Immun. 2016;84(6):1796-1805.

70. Ren T, Zamboni DS, Roy CR, Dietrich WF, Vance RE. Flagellin-deficient Legionella mutants evade caspase-1- and Naip5-mediated macrophage immunity. PLoS Pathog. 2006;2(3):e18.

71. Bierschenk D, Monteleone M, Moghaddas F, et al. The Salmonella pathogenicity island-2 subverts human NLRP3 and NLRC4 inflammasome responses. J Leukoc Biol. 2019;105(2):401-410.

72. Kupz A, Guarda G, Gebhardt T, et al. NLRC4 inflammasomes in dendritic cells regulate noncognate effector function by memory CD8(+) T cells. Nat Immunol. 2012;13(2):162-169.

73. Hornick EE, Dagvadorj J, Zacharias ZR, et al. Dendritic cell NLRC4 regulates influenza A virus-specific CD4 T cell responses through FasL expression. J Clin Invest. 2019;129(7):2888-2897.

74. Perez-Lopez A, Rosales-Reyes R, Alpuche-Aranda CM, Ortiz-Navarrete V. Salmonella downregulates Nod-like receptor family CARD domain containing protein 4 
expression to promote its survival in B cells by preventing inflammasome activation and cell death. J Immunol. 2013;190(3):1201-1209.

75. Chen KW, Gross CJ, Sotomayor FV, et al. The neutrophil NLRC4 inflammasome selectively promotes IL-1beta maturation without pyroptosis during acute Salmonella challenge. Cell Rep. 2014;8(2):570-582.

76. Nichols RD, von Moltke J, Vance RE. NAIP/NLRC4 inflammasome activation in MRP8(+) cells is sufficient to cause systemic inflammatory disease. Nat Commun. 2017;8(1):2209.

77. Chen KW, Monteleone M, Boucher D, et al. Noncanonical inflammasome signaling elicits gasdermin D-dependent neutrophil extracellular traps. Sci Immunol. 2018;3(26).

78. Patankar YR, Mabaera R, Berwin B. Differential ASC requirements reveal a key role for neutrophils and a noncanonical IL-1beta response to Pseudomonas aeruginosa. Am J Physiol Lung Cell Mol Physiol. 2015;309(8):L902-913.

79. Nordlander S, Pott J, Maloy KJ. NLRC4 expression in intestinal epithelial cells mediates protection against an enteric pathogen. Mucosal Immunol. 2014;7(4):775785.

80. Sellin ME, Muller AA, Felmy B, et al. Epithelium-intrinsic NAIP/NLRC4 inflammasome drives infected enterocyte expulsion to restrict Salmonella replication in the intestinal mucosa. Cell Host Microbe. 2014;16(2):237-248.

81. Rauch I, Deets KA, Ji DX, et al. NAIP-NLRC4 Inflammasomes Coordinate Intestinal Epithelial Cell Expulsion with Eicosanoid and IL-18 Release via Activation of Caspase1 and -8. Immunity. 2017;46(4):649-659.

82. Freeman L, Guo H, David CN, Brickey WJ, Jha S, Ting JP. NLR members NLRC4 and NLRP3 mediate sterile inflammasome activation in microglia and astrocytes. J Exp Med. 2017;214(5):1351-1370.

83. Liu L, Chan C. IPAF inflammasome is involved in interleukin-1beta production from astrocytes, induced by palmitate; implications for Alzheimer's Disease. Neurobiol Aging. 2014;35(2):309-321.

84. Poh L, Kang SW, Baik SH, et al. Evidence that NLRC4 inflammasome mediates apoptotic and pyroptotic microglial death following ischemic stroke. Brain Behav Immun. 2019;75:34-47.

85. Denes A, Coutts G, Lenart N, et al. AIM2 and NLRC4 inflammasomes contribute with ASC to acute brain injury independently of NLRP3. Proc Natl Acad Sci U S A. 2015;112(13):4050-4055.

86. Lara-Tejero $\mathrm{M}$, Sutterwala FS, Ogura $\mathrm{Y}$, et al. Role of the caspase-1 inflammasome in Salmonella typhimurium pathogenesis. J Exp Med. 2006;203(6):1407-1412.

87. Franchi L, Kamada N, Nakamura Y, et al. NLRC4-driven production of IL-1beta discriminates between pathogenic and commensal bacteria and promotes host intestinal defense. Nat Immunol. 2012;13(5):449-456.

88. Hausmann A, Bock D, Geiser P, et al. Intestinal epithelial NAIP/NLRC4 restricts systemic dissemination of the adapted pathogen Salmonella Typhimurium due to site-specific bacterial PAMP expression. Mucosal Immunol. 2020;13(3):530-544.

89. Miao EA, Leaf IA, Treuting PM, et al. Caspase-1-induced pyroptosis is an innate immune effector mechanism against intracellular bacteria. Nat Immunol.

2010;11(12):1136-1142. 
90. Masumoto J, Dowds TA, Schaner P, et al. ASC is an activating adaptor for NF-kappa B and caspase-8-dependent apoptosis. Biochem Biophys Res Commun. 2003;303(1):6973.

91. Man SM, Tourlomousis P, Hopkins L, Monie TP, Fitzgerald KA, Bryant CE. Salmonella infection induces recruitment of Caspase-8 to the inflammasome to modulate IL1beta production. J Immunol. 2013;191(10):5239-5246.

92. Vajjhala PR, Lu A, Brown DL, et al. The Inflammasome Adaptor ASC Induces Procaspase-8 Death Effector Domain Filaments. J Biol Chem. 2015;290(49):2921729230.

93. Christgen $\mathrm{S}$, Zheng $\mathrm{M}$, Kesavardhana $\mathrm{S}$, et al. Identification of the PANoptosome: A Molecular Platform Triggering Pyroptosis, Apoptosis, and Necroptosis (PANoptosis). Front Cell Infect Microbiol. 2020;10:237.

94. Man SM. Inflammasomes in the gastrointestinal tract: infection, cancer and gut microbiota homeostasis. Nat Rev Gastroenterol Hepatol. 2018;15(12):721-737.

95. Semper RP, Vieth M, Gerhard M, Mejias-Luque R. Helicobacter pylori Exploits the NLRC4 Inflammasome to Dampen Host Defenses. J Immunol. 2019;203(8):21832193.

96. Goncalves AV, Margolis SR, Quirino GFS, et al. Gasdermin-D and Caspase-7 are the key Caspase-1/8 substrates downstream of the NAIP5/NLRC4 inflammasome required for restriction of Legionella pneumophila. PLoS Pathog. 2019;15(6):e1007886.

97. Cerqueira DM, Pereira MS, Silva AL, Cunha LD, Zamboni DS. Caspase-1 but Not Caspase-11 Is Required for NLRC4-Mediated Pyroptosis and Restriction of Infection by Flagellated Legionella Species in Mouse Macrophages and In Vivo. J Immunol. 2015;195(5):2303-2311.

98. Pereira MS, Morgantetti GF, Massis LM, Horta CV, Hori JI, Zamboni DS. Activation of NLRC4 by flagellated bacteria triggers caspase-1-dependent and -independent responses to restrict Legionella pneumophila replication in macrophages and in vivo. J Immunol. 2011;187(12):6447-6455.

99. Pereira MS, Marques GG, Dellama JE, Zamboni DS. The NIrc4 Inflammasome Contributes to Restriction of Pulmonary Infection by Flagellated Legionella spp. that Trigger Pyroptosis. Front Microbiol. 2011;2:33.

100. Silveira TN, Zamboni DS. Pore formation triggered by Legionella spp. is an NIrc4 inflammasome-dependent host cell response that precedes pyroptosis. Infect Immun. 2010;78(3):1403-1413.

101. Lee BL, Mirrashidi KM, Stowe IB, et al. ASC- and caspase-8-dependent apoptotic pathway diverges from the NLRC4 inflammasome in macrophages. Sci Rep. 2018;8(1):3788.

102. Lamkanfi M, Kanneganti TD, Van Damme $P$, et al. Targeted peptidecentric proteomics reveals caspase- 7 as a substrate of the caspase- 1 inflammasomes. Mol Cell Proteomics. 2008;7(12):2350-2363.

103. Man SM, Ekpenyong A, Tourlomousis P, et al. Actin polymerization as a key innate immune effector mechanism to control Salmonella infection. Proc Natl Acad Sci U S A. 2014;111(49):17588-17593.

104. McClellan SA, Jerome A, Suvas S, Hazlett LD. NLRC4 regulates caspase-1 and IL-1beta production in a CD11blowLy6Glow population of cells required for resistance to Pseudomonas aeruginosa keratitis. PLoS One. 2017;12(9):e0185718. 
105. Sutterwala FS, Mijares LA, Li L, Ogura Y, Kazmierczak BI, Flavell RA. Immune recognition of Pseudomonas aeruginosa mediated by the IPAF/NLRC4 inflammasome. J Exp Med. 2007;204(13):3235-3245.

106. Cohen TS, Prince AS. Activation of inflammasome signaling mediates pathology of acute P. aeruginosa pneumonia. J Clin Invest. 2013;123(4):1630-1637.

107. Ayres JS, Trinidad NJ, Vance RE. Lethal inflammasome activation by a multidrugresistant pathobiont upon antibiotic disruption of the microbiota. Nat Med. 2012;18(5):799-806.

108. von Moltke J, Trinidad NJ, Moayeri M, et al. Rapid induction of inflammatory lipid mediators by the inflammasome in vivo. Nature. 2012;490(7418):107-111.

109. Romberg N, Al Moussawi K, Nelson-Williams C, et al. Mutation of NLRC4 causes a syndrome of enterocolitis and autoinflammation. Nat Genet. 2014;46(10):11351139.

110. Barsalou J, Blincoe A, Fernandez I, et al. Rapamycin as an Adjunctive Therapy for NLRC4 Associated Macrophage Activation Syndrome. Front Immunol. 2018;9:2162.

111. Canna SW, de Jesus AA, Gouni S, et al. An activating NLRC4 inflammasome mutation causes autoinflammation with recurrent macrophage activation syndrome. Nat Genet. 2014;46(10):1140-1146.

112. Moghaddas F, Zeng $P$, Zhang Y, et al. Autoinflammatory mutation in NLRC4 reveals a leucine-rich repeat (LRR)-LRR oligomerization interface. J Allergy Clin Immunol. 2018;142(6):1956-1967 e1956.

113. Chear CT, Nallusamy R, Canna SW, et al. A novel de novo NLRC4 mutation reinforces the likely pathogenicity of specific LRR domain mutation. Clin Immunol. 2020;211:108328.

114. Kawasaki Y, Oda H, Ito J, et al. Identification of a High-Frequency Somatic NLRC4 Mutation as a Cause of Autoinflammation by Pluripotent Cell-Based Phenotype Dissection. Arthritis Rheumatol. 2017;69(2):447-459.

115. Volker-Touw CM, de Koning HD, Giltay JC, et al. Erythematous nodes, urticarial rash and arthralgias in a large pedigree with NLRC4-related autoinflammatory disease, expansion of the phenotype. Br J Dermatol. 2017;176(1):244-248.

116. Kitamura A, Sasaki Y, Abe T, Kano H, Yasutomo K. An inherited mutation in NLRC4 causes autoinflammation in human and mice. J Exp Med. 2014;211(12):2385-2396.

117. Canna SW, Girard C, Malle L, et al. Life-threatening NLRC4-associated hyperinflammation successfully treated with IL-18 inhibition. J Allergy Clin Immunol. 2017;139(5):1698-1701.

118. Liu R, Truax AD, Chen L, et al. Expression profile of innate immune receptors, NLRs and AIM2, in human colorectal cancer: correlation with cancer stages and inflammasome components. Oncotarget. 2015;6(32):33456-33469.

119. Kong $H$, Wang $Y$, Zeng $X$, Wang $Z$, Wang $H$, Xie W. Differential expression of inflammasomes in lung cancer cell lines and tissues. Tumour Biol. 2015;36(10):75017513.

120. Wang $X$, Yang $C$, Liao $X$, et al. NLRC and NLRX gene family mRNA expression and prognostic value in hepatocellular carcinoma. Cancer Med. 2017;6(11):2660-2672.

121. Jin H, Kim HJ. NLRC4, ASC and Caspase-1 Are Inflammasome Components that Are Mediated by P2Y2R Activation in Breast Cancer Cells. Int J Mol Sci. 2020;21(9).

122. Sharma N, Saxena S, Agrawal I, et al. Differential Expression Profile of NLRs and AIM2 in Glioma and Implications for NLRP12 in Glioblastoma. Sci Rep. 2019;9(1):8480. 
123. Hu B, Elinav $E$, Huber $S$, et al. Inflammation-induced tumorigenesis in the colon is regulated by caspase-1 and NLRC4. Proc Natl Acad Sci U S A. 2010;107(50):2163521640.

124. Allen IC, TeKippe EM, Woodford RM, et al. The NLRP3 inflammasome functions as a negative regulator of tumorigenesis during colitis-associated cancer. $J$ Exp Med. 2010;207(5):1045-1056.

125. Carvalho FA, Nalbantoglu I, Aitken JD, et al. Cytosolic flagellin receptor NLRC4 protects mice against mucosal and systemic challenges. Mucosal Immunol. 2012;5(3):288-298.

126. Janowski AM, Colegio OR, Hornick EE, et al. NLRC4 suppresses melanoma tumor progression independently of inflammasome activation. $J$ Clin Invest. 2016;126(10):3917-3928.

127. Simon MM, Greenaway S, White JK, et al. A comparative phenotypic and genomic analysis of C57BL/6J and C57BL/6N mouse strains. Genome Biol. 2013;14(7):R82.

128. Kolb R, Phan L, Borcherding N, et al. Obesity-associated NLRC4 inflammasome activation drives breast cancer progression. Nat Commun. 2016;7:13007.

129. Ohashi K, Wang Z, Yang YM, et al. NOD-like receptor C4 Inflammasome Regulates the Growth of Colon Cancer Liver Metastasis in NAFLD. Hepatology. 2019;70(5):15821599.

130. Lim J, Kim MJ, Park Y, et al. Upregulation of the NLRC4 inflammasome contributes to poor prognosis in glioma patients. Sci Rep. 2019;9(1):7895.

131. Sakuma C, Toki D, Shinkai $\mathrm{H}$, et al. Pig lacks functional NLRC4 and NAIP genes. Immunogenetics. 2017;69(2):125-130.

132. Liang J, Alfano DN, Squires JE, et al. Novel NLRC4 Mutation Causes a Syndrome of Perinatal Autoinflammation With Hemophagocytic Lymphohistiocytosis, Hepatosplenomegaly, Fetal Thrombotic Vasculopathy, and Congenital Anemia and Ascites. Pediatr Dev Pathol. 2017;20(6):498-505. 


\section{FIGURE LEGENDS}

Figure 1. Mechanisms of NAIP-NLRC4 inflammasome activation (A). Both NAIPs and NLRC4 contain a central NBD domain with associated domains (HD1, WHD, HD2) and a C-terminal LRR. In addition, NAIPs contain an N-terminal BIR domain and NLRC4 contains an N-terminal CARD. The domain architecture is conserved between mice and humans. (B) Bacterial ligands including the needle and inner rod protein of the Type 3 secretion system and the flagellin monomer of the flagellar apparatus can be recognized by NAIP proteins, which associate with NLRC4 to induce activation of the NAIP-NLRC4 inflammasome. This pathway results in the cleavage and activation of caspase-1, which mediates cleavage of Gasdermin D and the immature cytokines pro-IL-1 $\beta$ and pro-IL-18. Cleavage of Gasdermin D induces pyroptosis via the formation of membrane pores. Cleavage of the immature cytokines enables their secretion via Gasdermin D pores and induces inflammation. NAIPs are transcriptionally induced by IRF8. Phosphorylation of NLRC4 by the kinase PKCס or LRRK2 might, in part, contribute to the activation of the inflammasome (indicated by the dashed arrow).

Figure 2. Expression of NAIP-NLRC4 inflammasome components in mice. Abbreviations: ASC, apoptosis-associated speck-like protein containing a caspase activation and recruitment domain; IL-1 $\beta$, interleukin-1 $\beta$; IL-18, interleukin-18; NAIPs, NLR apoptosis inhibitory proteins; NLRC, nucleotide-binding domain, leucine-rich repeat containing protein containing a caspase activation and recruitment domain.

Figure 3. Expression of NAIP-NLRC4 inflammasome components in humans. Abbreviations: ASC, apoptosis-associated speck-like protein containing a caspase activation and recruitment domain; IL-1 $\beta$, interleukin-1 $\beta$; IL-18, interleukin-18; NAIP, NLR apoptosis inhibitory protein; NLRC, nucleotide-binding domain, leucine-rich repeat containing protein containing a caspase activation and recruitment domain. 


\section{A}

NAIP

BIR

\begin{tabular}{l|l|l|l|} 
NBD & HD1 & WHD & HD2 \\
\hline
\end{tabular}

LRR

NLRC4

CARD

\begin{tabular}{l|l|l|l|} 
NBD & HD1 & WHD & HD2 \\
\hline
\end{tabular}

LRR

B

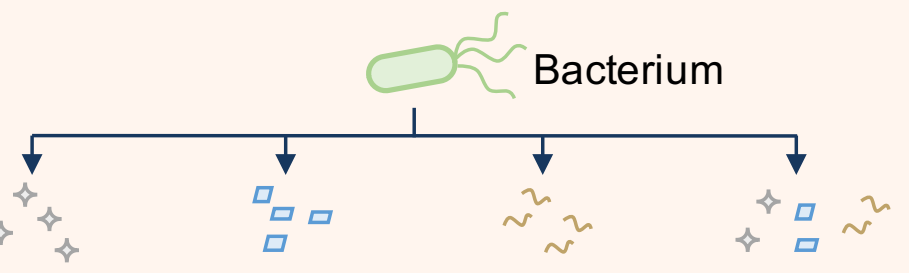

Needle Inner rod Flagellin Needle, inner

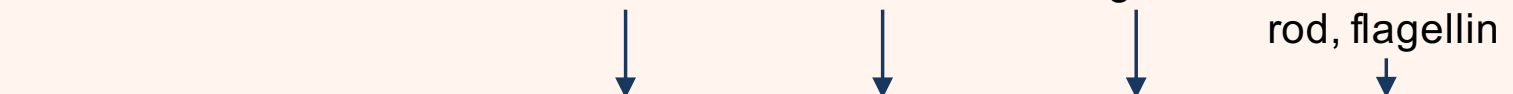

IRF8

NAIP 1

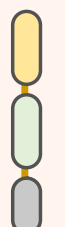

NAIP2

NAIP5/6
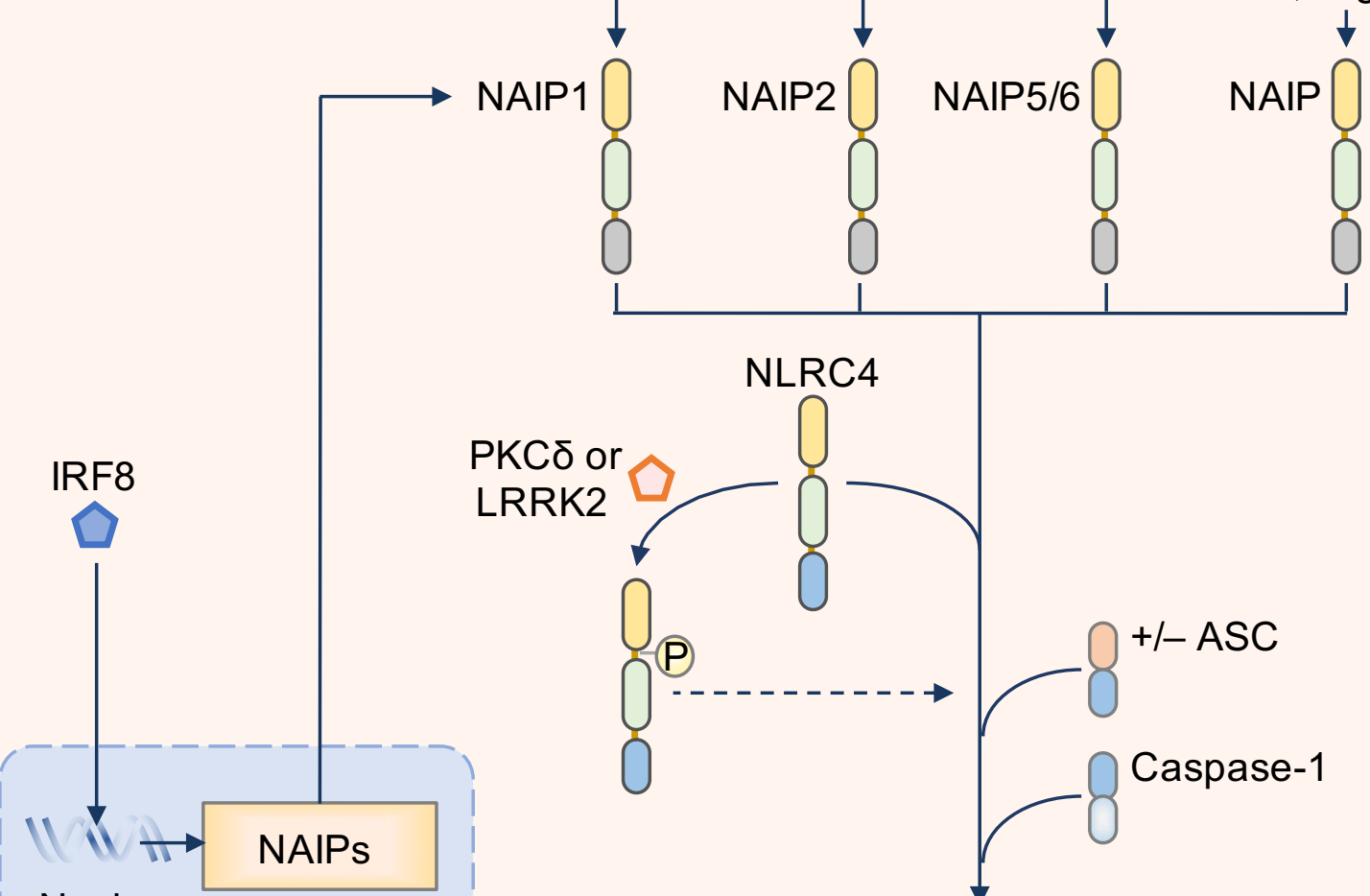

LRRK2

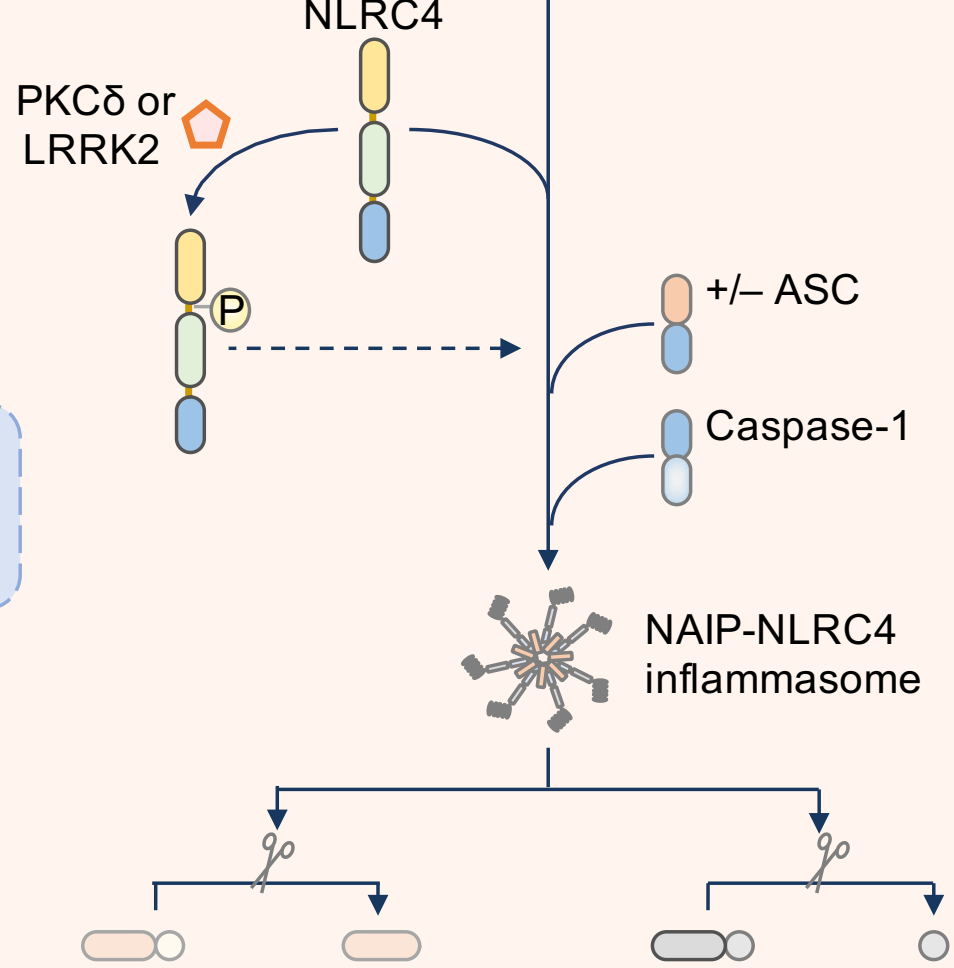

Nucleus

Gasdermin D N-terminal

Pro-IL-1 $\quad$ IL-1 $\beta$

Pyroptosis

Pro-IL-18 IL-18

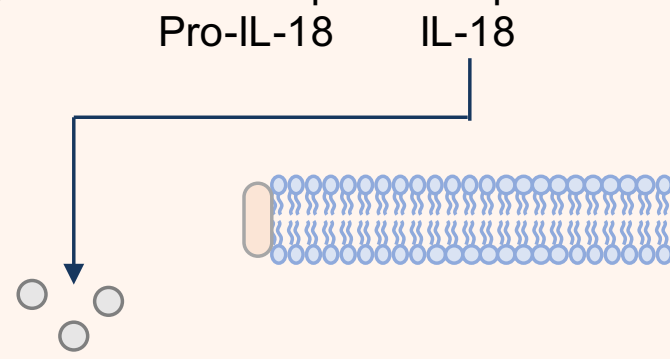




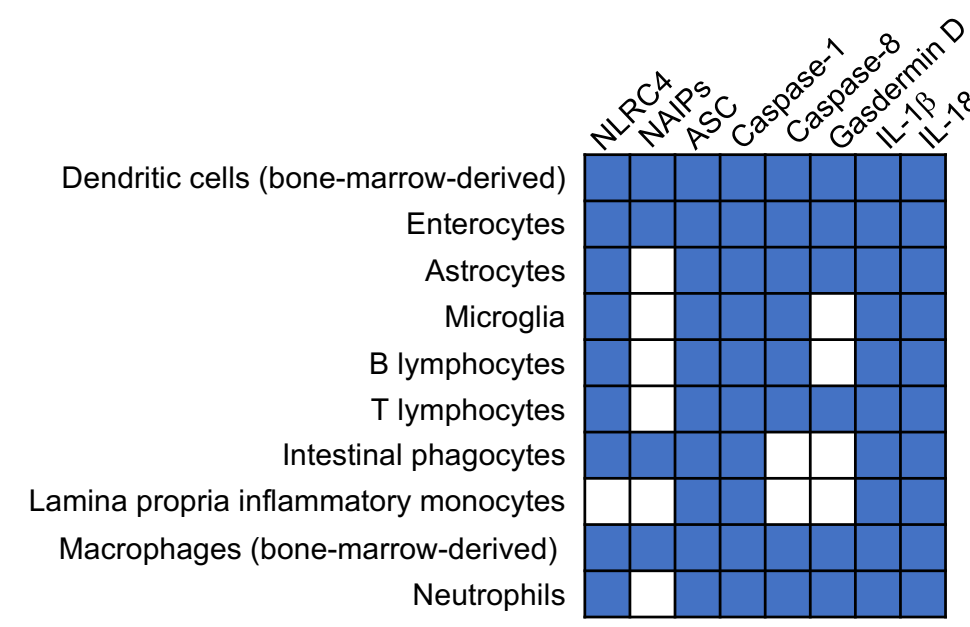

Expression reported

$\square$ Expression not reported or unknown

Figure 2 


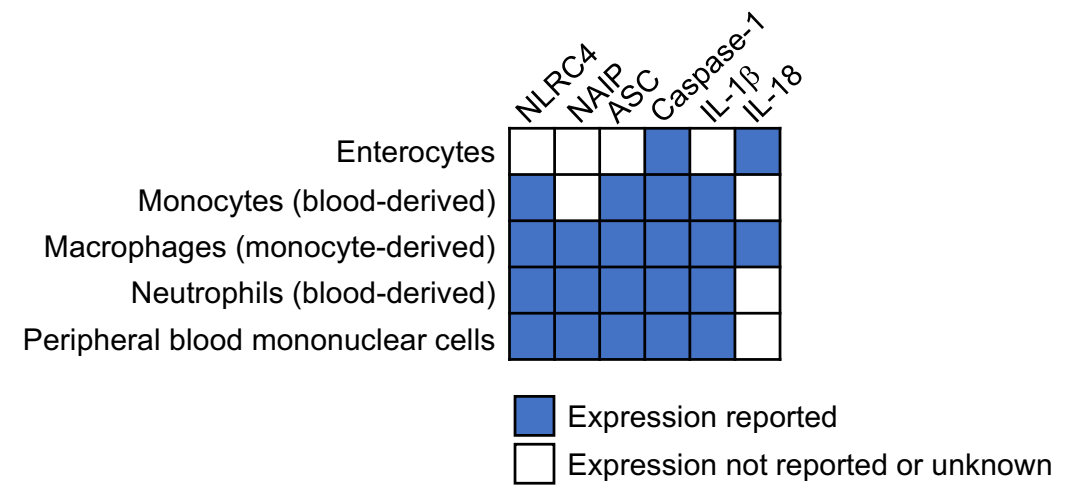

Figure 3 